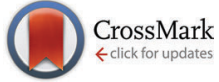

Cite this: J. Mater. Chem. C, 2015, 3, 9701

\title{
Properties modulation of organic semi-conductors based on a donor-spiro-acceptor (D-spiro-A) molecular design: new host materials for efficient sky-blue PhOLEDs†
}

\author{
Maxime Romain, ${ }^{a}$ Denis Tondelier, ${ }^{b}$ Olivier Jeannin, ${ }^{a}$ Bernard Geffroy, ${ }^{\text {bc }}$ \\ Joëlle Rault-Berthelot*a and Cyril Poriel*a
}

Received 18th June 2015,

Accepted 31st July 2015

DOI: $10.1039 / \mathrm{c} 5 \mathrm{tc} 01812 \mathrm{a}$

www.rsc.org/MaterialsC
Four high triplet organic semi-conductors based on the donor-spiro-acceptor design (D-spiro-A) have been synthesized. Their physicochemical and photophysical properties have been studied, compared and discussed in light of the nature of their respective donor/acceptor units. The four compounds have been used as host materials in efficient sky-blue (EQE $>10 \%$ at $10 \mathrm{~mA} \mathrm{~cm}{ }^{-2}$ ) phosphorescent organic light emitting diodes.
In the last twenty years, many families of organic emissive materials have been developed for flat-panel displays and solid state lighting sources. ${ }^{1-3}$ The design of fluorescent organic semi-conductors for green and red emission has led to highly efficient organic light emitting diodes (OLEDs). ${ }^{4}$ However, the blue colour, despite fantastic recent progresses in the design of fluorescent materials ${ }^{5-12}$ and in the device architectures, ${ }^{13}$ remains less efficient and less stable than the other colours. ${ }^{4}$ In addition, in the last fifteen years, it has been demonstrated that highly efficient blue emission should not be obtained in OLED devices using pure organic singlet exciton emissive layers (EMLs) but should require more sophisticated EMLs in which a blue phosphor is doped in an organic host material to harvest both singlet and triplet excitons. Such devices, phosphorescent organic light emitting diodes (PhOLEDs), have therefore attracted fantastic interest. ${ }^{14-18}$ One of the weakest links of this technology remaining is the design of highly efficient host materials for blue phosphors. Indeed, the prerequisites for an ideal host for a blue dopant are (i) a high triplet energy $\left(E_{\mathrm{T}}\right)$ to avoid reverse energy transfers from the guest back to the host, (ii) a high glasstransition temperature $\left(T_{\mathrm{g}}\right)$ and decomposition temperature $\left(T_{\mathrm{d}}\right)$

\footnotetext{
${ }^{a}$ UMR CNRS 6226, Institut des Sciences Chimiques de Rennes, Université de Rennes 1 , Campus de Beaulieu, 35042 Rennes cedex, France. E-mail: cyril.poriel@univ-rennes1.fr, joelle.rault-berthelot@univ-rennes1.fr; Tel: +33-2-2323-5977

${ }^{b}$ UMR CNRS 7647, LPCIM, École Polytechnique, 91128 Palaiseau, France.

E-mail: bernard.geffroy@polytechnique.edu

${ }^{c}$ LICSEN/NIMBE UMR 3685, CEA Saclay, 91191 Gif Sur Yvette, France

$\dagger$ Electronic supplementary information (ESI) available: Materials and methods and experimental details; synthesis and characterization of all compounds, absorption spectra in various solvents, DSC, a copy of the NMR spectra, and green device performance. CCDC 1046694-1046697 and 1046704. For ESI and crystallographic data in CIF or other electronic format see DOI: 10.1039/c5tc01812a
}

for stability, (iii) matching HOMO-LUMO levels for injection of the charges and (iv) good and balanced charge transporting properties to insure efficient recombination in the dopant. For industrial production, long and sophisticated chemical syntheses of the host should be also clearly proscribed. Bipolar molecules incorporating hole and electron transporting units to adjust the energy levels of frontier orbitals appear to date to be the most promising candidates for PhOLED applications. ${ }^{2,16-22}$ Thus, when designing bipolar hosts, one should carefully consider the selection of the donor/acceptor pair and their relative positions within the dye. Indeed, the donor/acceptor combination often results in $\pi$-conjugation enlargement, which would accordingly reduce the singlet and triplet energies. Therefore, to obtain bipolar hosts with high $E_{\mathrm{T}}$, the $\pi$-conjugation and the electronic coupling between the donor and the acceptor units must be restricted. The choice of the linker and the relative position of the donor and acceptor units must then be carefully performed.

To date, many successful design strategies have been developed to gather all the above mentioned properties in a single host and particularly to disrupt the $\pi$-conjugation. Some relevant examples are presented in Chart 1.

First, it is known that electronic coupling through a meta linkage is inherently weaker than that through a para one $\mathrm{e}^{5,23-27}$ and this strategy has often been used to connect a hole transporting and an electron transporting unit in a host material. ${ }^{21,24,28,29}$ Thus, the meta linkages efficiently disrupt the $\pi$-conjugation between a donor and an acceptor as for instance in 9-(3-(diphenylcarbazol-3-yl)phenyl)- $\alpha$-carboline (PCb-PCz, Chart 1), in which the $N$-phenylcarbazole donor unit is separated from the pyridoindole acceptor unit by a meta-substituted phenyl unit (HOMO: $-5.75 \mathrm{eV}$, LUMO: $\left.-2.31 \mathrm{eV}, E_{\mathrm{T}}=2.74 \mathrm{eV}\right) .{ }^{21}$ A second approach widely developed in the literature consists of introducing steric congestion 


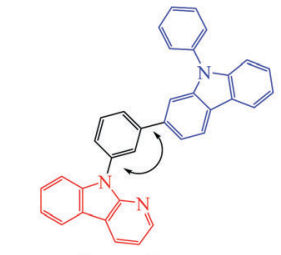

$\mathrm{PCb}-\mathrm{PCz}$

Meta linkage (electronic coupling)

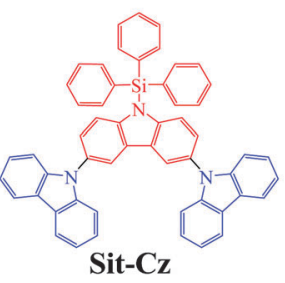

Triphenylsilane linkage (insulating $\mathrm{Si}$ atom)

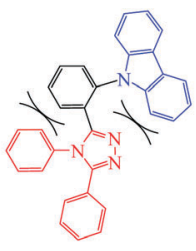

Taz-Cz

Ortho linkage (steric hindrance)

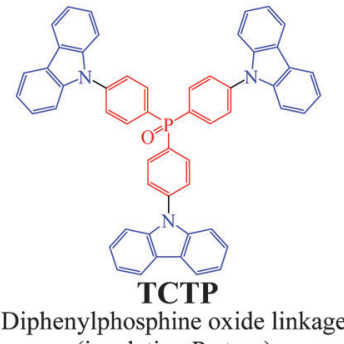

(insulating $\mathrm{P}$ atom)
Chart 1 Different design strategies for $\pi$-conjugation disruption

within the dye to hinder the planarization between two connected $\pi$-systems. ${ }^{30-33}$ This steric hindrance strategy is most of the time performed through the incorporation of a sterically hindered ortho linkage efficiently leading to $\pi$-conjugation restriction. For example, in Taz-Cz (Chart 1), the carbazole and 1,2,4-triazole are both oriented with a dihedral angle larger than $45^{\circ}$ with the central benzene ring, efficiently disrupting the $\pi$-conjugation between the carbazole and the triazole (HOMO: $-5.7 \mathrm{eV}$, LUMO: $\left.-2.3 \mathrm{eV}, E_{\mathrm{T}}=3.09 \mathrm{eV}\right){ }^{31}$

Using an insulating heteroatom is also an efficient strategy to obtain high $E_{\mathrm{T}}$ materials with a short $\pi$-conjugated pathway. Thus, silicium (silane), ${ }^{2,18,34,35}$ and a phosphoryl group $(\mathrm{P}=\mathrm{O}),{ }^{2,18,20,29,36,37}$ may act as effective breaking points of the $\pi$-conjugation between the main core of the molecule and the outer groups linked to the heteroatom (phenyl, for example in the case of the efficient electron transporting diphenylphosphine oxide unit). Thus, the electronic structure of the bipolar molecules is almost identical to those of the corresponding central core, which is a crucial point to avoid the decrease of $E_{\mathrm{T}}{ }^{20}$ For example, in $9^{\prime}$-triphenylsilanyl$9^{\prime} H-\left[9,3^{\prime}, 6^{\prime}, 9^{\prime \prime}\right]$ ter-carbazole (Sit-Cz), the direct connection of the silane to a carbazole unit through the nitrogen atom renders this carbazole electro-deficient (HOMO: $-5.54 \mathrm{eV}$, LUMO: $-2.3 \mathrm{eV}$, $\left.E_{\mathrm{T}}=3.0 \mathrm{eV}\right) .^{38}$ Similarly, in the star-shaped molecule $4,4^{\prime}, 4^{\prime \prime}$ tri( $N$-carbazolyl)triphenylphosphine oxide (TCTP), the electron acceptor phosphine oxide unit is used both as the core and as the electron donor, with the carbazole moiety acting as the branch. ${ }^{39}$ The HOMO/LUMO levels respectively lie at $-5.25 \mathrm{eV} /$ $-1.67 \mathrm{eV}$, and the disrupted conjugation via the phosphine oxide linkage preserves a high $E_{\mathrm{T}}$ of $3.03 \mathrm{eV}$.

More recently, another promising and simple molecular design based on $\pi$-conjugation breaking induced by an insulating spiro bridge (called a D-spiro-A design) has been introduced in the literature. This design, which allows separation of the HOMO and LUMO levels, has a great potential in thermally activated delayed fluorescence (TADF) $)^{40,41}$ but remains rarely
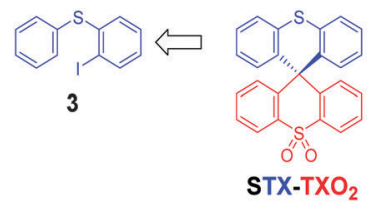

STX-TXO
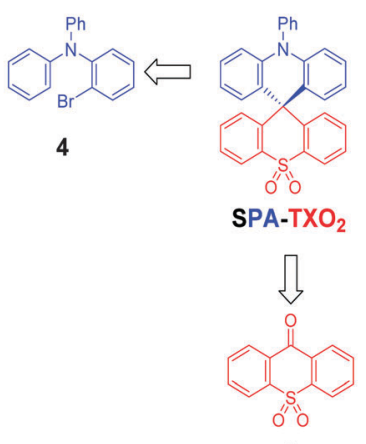

1
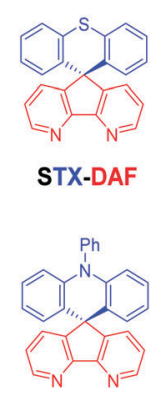

SPA-DAF

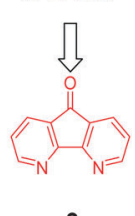

2
Scheme 1 Retrosynthetic analysis of the four dyes investigated in this work: STX-TXO ${ }_{2}$, STX-DAF, SPA-TXO 2 and SPA-DAF.

used to date in the field of host materials for blue phosphorescent dopants. ${ }^{35,42-44}$ Our attention for this design was to avoid the introduction of pendant hole or electron transporting units, strongly simplifying the molecular structure and hence the chemical synthesis. In the present work, we wish to report a structure-properties relationship study of new donor/acceptor molecules based on this D-spiro-A design. These semi-conductors present different electronic properties and have been used as hosts in sky-blue PhOLEDs leading in some cases to high efficiencies (EQE $>10 \%$ at $10 \mathrm{~mA} \mathrm{~cm} \mathrm{~cm}^{-2}$ ). The large differences observed in terms of PhOLED efficiencies highlight the importance of the donor/acceptor combination used in the molecular design of the host. Such a structure-properties relationship study may provide interesting insights for the development of future materials for optoelectronics. Thus, in this work, as a development to our preliminary note on the dye $\mathbf{S P A - T X \mathbf { O } _ { 2 }}$ (Scheme 1), ${ }^{45}$ we have investigated through a D-spiro-A design two hole transporting moieties, namely $N$-phenylacridine $(\mathrm{PA})^{43}$ and thioxanthene (TX), and two electron transporting moieties, namely thioxanthene dioxide $\left(\mathrm{TXO}_{2}\right)$ and diazafluorene (DAF) (Scheme 1). These four molecular fragments are briefly described below.

In PA, two phenyl rings of a triphenylamine unit are connected by a methylene unit forming a hexagon. Structurally, the presence of this hexagon renders the $N$-phenylacridine unit more similar to a triphenylamine than to a $N$-phenylcarbazole unit. ${ }^{46}$ The strong electron rich nature of the PA unit has been previously exploited in TADF, ${ }^{40,41,47}$ in non-doped blue OLEDs ${ }^{48}$ and in host materials for blue PhOLEDs. ${ }^{35,42,43,49,50}$

TX is the structural analogue of xanthene, possessing an intracyclic sulphur atom instead of an oxygen atom. Recently, Yam et al. have reported various spiro-configured dyes based on the connection of a TX (and $\mathrm{TXO}_{2}$ ) unit with 2,7-bis(diphenylamine)fluorene leading to very promising donor materials in the construction of high performance organic photovoltaic devices. ${ }^{51}$

$\mathrm{TXO}_{2}$ is the oxidized analogue of TX. The presence of the sulfone in $\mathrm{TXO}_{2}$ leads to better electron injection and transport 
abilities due to the decrease of the LUMO level. ${ }^{12}$ Indeed, sulfones have been efficiently incorporated (i) in highly efficient blue emitting materials, ${ }^{52-54}$ (ii) in host materials for PhOLEDs, ${ }^{55-57}$ and (iii) in electron transporting materials. ${ }^{58}$ However, the use of the $\mathrm{TXO}_{2}$ fragment remains scarce and our group, in a preliminary note, has recently demonstrated its potential in the design of hosts for blue PhOLEDs. ${ }^{45}$ Thus, by a simple oxidation step, it is hence possible to switch from hole transporting properties in TX to electron transporting properties in $\mathrm{TXO}_{2}$, highlighting the versatility of these systems.

The electron acceptor DAF may be regarded as a bipyridine unit possessing then a similar molecular arrangement to that of the well-known bridged biphenyl, namely fluorene. The strong electron affinity of this unit ${ }^{59,60}$ could decrease the LUMO energy level, thereby improving the electron injection and transport properties of the materials. Up to now, DAF fragments have been investigated in many research fields, such as electron transporting materials, ${ }^{61}$ organic emitters, ${ }^{59,62}$ and sensors. ${ }^{63}$ The DAF fragment is also an interesting platform to coordinate various metals such as cadmium, ${ }^{64}$ zinc, $^{64}$ rhenium, ${ }^{65}$ silver $^{66}$ and iridium. ${ }^{67,68}$ However, to the best of our knowledge, the DAF unit remains rarely incorporated in host materials for PhOLEDs. ${ }^{60,61,69}$

\section{Results and discussion}

\section{Synthesis}

It is crucial for the future of organic optoelectronics to establish short and very efficient synthetic approaches of organic materials. Herein, all the dyes have been synthesised through a one-pot very efficient route using common and easily synthesizable intermediates. Thus, the two halogeno-aryls $\mathbf{3}$ and $\mathbf{4}$, judiciously coupled with the two ketones $\mathbf{1}$ and 2, provide $\mathbf{S T X}-\mathbf{T X O}_{\mathbf{2}}(\mathbf{3}+\mathbf{1})$, STX-DAF $(3+2)$, SPA-TXO $_{2}(4+1)$ and SPA-DAF $(4+2)$ (Scheme 1).

Regarding the $\mathrm{TXO}_{2}$ derivative (Scheme 2, top), a lithiumbromine exchange was first performed on either 2-bromo- $N, N$ diphenylaniline 4 or (2-iodophenyl)(phenyl)sulfane 3 followed by the trapping of the lithiated intermediate by ketone $9 H$-thioxanthen-9-one-10,10-dioxide 1 (obtained by oxidation of commercially available $9 H$-thioxanthen-9-one with hydrogen peroxide, see ESI $\dagger$ ). An electrophilic intramolecular cyclization reaction of the resulting dioxothioxanthenols (not isolated) in acidic media ( $\mathrm{HCl}$ in acetic acid) afforded SPA-TXO $\mathbf{S}_{2}$ or $\mathbf{S T X}-\mathbf{T X O}$ in high yields (78 and 88\% respectively over the three steps). This one-pot synthetic strategy is very simple, easy to perform, highly efficient for a gram scale synthesis and is versatile to many different donor and acceptor fragments.

An identical strategy has been developed to synthesise STX-DAF and SPA-DAF (Scheme 2, bottom) involving first the synthesis of the known diazafluorenone 2 (obtained by oxidation and ring contraction of phenanthroline in water in the presence of $\mathrm{KMnO}_{4}$ and $\mathrm{KOH}$, see ESI $\left.\dagger\right){ }^{70}$ Reaction of 2 with the corresponding lithiated intermediates derived from 3 or 4 was then performed leading to the corresponding diazafluorenol derivatives. However the intramolecular cyclization reaction under similar conditions as those exposed above $\left(\mathrm{HCl} / \mathrm{CH}_{3} \mathrm{CO}_{2} \mathrm{H}\right.$, Scheme 2) did not occur, highlighting the very different reactivity of diazafluorenols $v s$. dioxothioxanthenols. The X-ray structure of the triphenylamine diazafluorenol shows short distances (ca. $2 \AA$, see Fig. S2 in the ESI $\dagger$ ) between a hydrogen atom of the hydroxide unit of one molecule and a nitrogen atom of the diazafluorene unit of a second molecule. These short distances signal the presence of intermolecular interactions that may explain the stabilization of diazafluorenol and hence its weak reactivity. In addition, the nitrogen atoms of the diazafluorene unit might be protonated during the cyclisation step, decreasing again its reactivity. Using more drastic conditions and 3 equivalents of methane sulfonic acid at high temperature $\left(180{ }^{\circ} \mathrm{C}\right.$ in 1,2 -dichlorobenzene), the target compounds STX-DAF (yield: 39\%) and SPA-DAF (yield: 47\%) were finally isolated. It should be noted that in the course of this work, the synthesis of SPA-DAF as an intermediate building block has been reported by Adachi and coworkers using Eaton's reagent to cyclise the diazafluorenol derivative. ${ }^{40}$ However, the properties of SPA-DAF were not reported in this work.
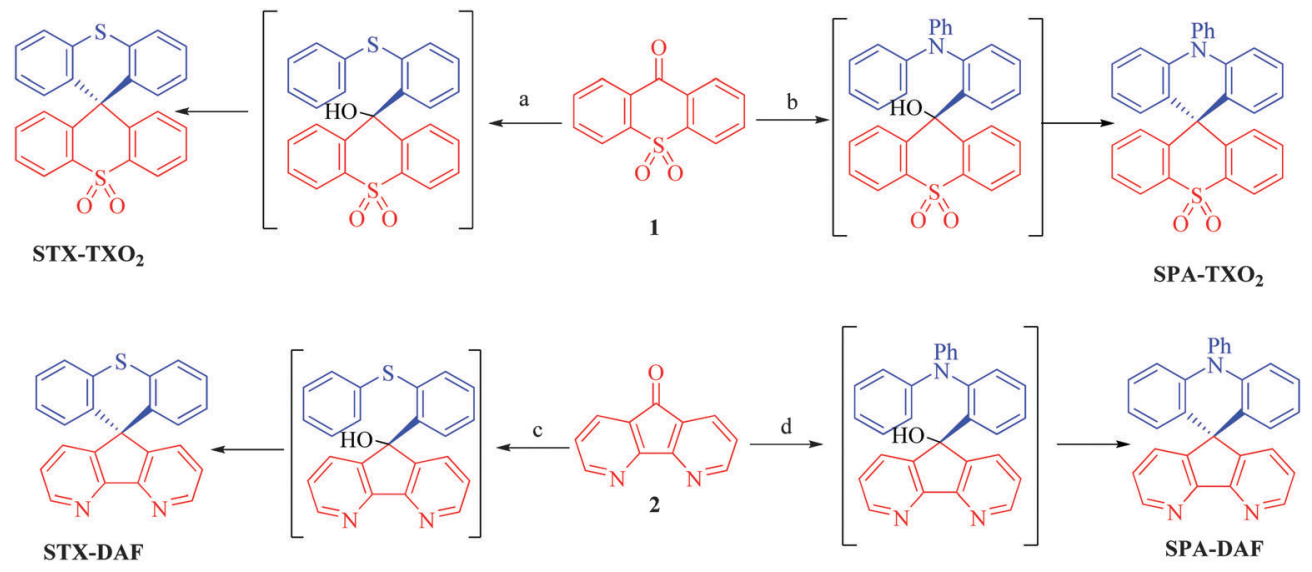

Scheme 2 Synthesis of STX-TXO 2, SPA-TXO 2, STX-DAF and SPA-DAF. (a) (2-lodophenyl)(phenyl)sulfane $3, n B u L i, ~ T H F$ from $-80{ }^{\circ} \mathrm{C}$ to $20{ }^{\circ} \mathrm{C}$ then $\mathrm{HCl}, \mathrm{AcOH}$ and reflux, $88 \%$ yield and (b) 2-bromo- $N, N$-diphenylamine $4, n B u L i$, THF from $-80{ }^{\circ} \mathrm{C}$ to $20{ }^{\circ} \mathrm{C}$ then $\mathrm{HCl}, \mathrm{AcOH}$ and reflux, $78 \%$ yield. (c) (2-lodophenyl)(phenyl)sulfane $3, n \mathrm{BuLi}, \mathrm{THF}$ from $-80{ }^{\circ} \mathrm{C}$ to $20^{\circ} \mathrm{C}$ then $\mathrm{MsOH}, 1,2$-dichlorobenzene and reflux, 39\% yield and (d) 2-bromo- $N, N$-diphenylaniline, $n$ BuLi, THF from $-80^{\circ} \mathrm{C}$ to $20^{\circ} \mathrm{C}$ then $\mathrm{MsOH}, 1,2$-dichlorobenzene and reflux, $47 \%$ yield. 


\section{${ }^{1}$ H NMR studies}

${ }^{1} \mathrm{H}$ NMR spectroscopy is an interesting tool to evaluate the strength of electron withdrawing/donating moieties on the environment. Thus, the effect of the incorporation of heteroatoms in the spirobifluorene-like molecules described herein can be interestingly visualized through NMR spectroscopy. The complete assignments of all signals have been performed by 2D NMR spectroscopy experiments (HMBC, HMQC, ${ }^{1} \mathrm{H} /{ }^{1} \mathrm{H}$ COSY, see ESI $\dagger$ ).

For STX-TXO ${ }_{2}$ and SPA-TXO ${ }_{2}$, one can note that the hydrogen atoms (Ha-d) of the $\mathbf{T X O}_{2}$ fragment (Fig. 1a and b, red lines) are centred around $7.35 \mathrm{ppm}$ except for $\mathrm{Ha}$, which appears to be deshielded due to the proximity of the sulfone unit. Considering the chemical shift of benzene (7.35 ppm in $\left.\mathrm{CD}_{2} \mathrm{Cl}_{2}\right)^{71}$ one can conclude that $\mathrm{TXO}_{2}$ is a weak electron withdrawing unit. On the opposite side, the signals for $\mathrm{Hf}-\mathrm{h}$ of the TX unit and $\mathrm{Hl}-\mathrm{O}$ of the PA core appear to be shielded, highlighting their electron donating nature. We can note that the incorporation of the nitrogen atom within the PA unit leads to stronger shielding than that observed for sulphur in TX, highlighting the stronger electron donating nature of the former. This will be confirmed by electrochemistry (see below). It should be mentioned that the resonances of the pendant phenyl ring of $\mathrm{PA}(\mathrm{Hi}-\mathrm{k})$ are found at low field $(\delta 7.58 / 7.8 \mathrm{ppm})$ meaning that the free doublet of the nitrogen atom is conjugated with the acridine and not with the phenyl unit.

Similar effects have been detected for STX-DAF and SPA-DAF with in addition two very low field resonances recorded at 8 and $8.65 \mathrm{ppm}$ (respectively assigned to $\mathrm{Hc}$ in the $\gamma$ position and to $\mathrm{Ha}$ in the $\beta$ position of the nitrogen atom of DAF). This highlights the strong electron withdrawing nature of the DAF fragment.

\section{Structural properties}

The four compounds have been crystallized by vapour diffusion of pentane in $\mathrm{CDCl}_{3}$ solution in order to confirm their molecular structures by X-ray crystallography and to study the structural characteristics (see X-ray data in the ESI $\dagger$ ). STX-TXO $\mathbf{O}_{2}$ and SPA$\mathbf{T X O} \mathbf{O}_{2}$ both crystallized in a triclinic system. The STX-TXO $\mathbf{S}_{\mathbf{2}}$ asymmetric unit contains two different molecules and one molecule of $\mathbf{C D C l}_{3}$ whereas that of $\mathbf{S P A - T X O} \mathbf{O}_{2}$ contains only one molecule without the solvent. STX-DAF crystallizes in an orthorhombic system with only one molecule per unit and SPA-DAF crystallizes with two molecules of solvent in a monoclinic system.

The molecular radius of each molecule (distance from the spiro carbon atom to the farthest carbon atom, green arrow in Fig. 2) has been evaluated at 7.14 and 7.10 $\AA$ for $\mathbf{S P A}-\mathbf{T X O} \mathbf{O}_{2}$ and SPA-DAF respectively, and at 4.36 and $4.34 \AA$ for $\mathbf{S T X}-\mathbf{T X O}_{2}$ and STX-DAF respectively. For the four molecules, this radius is imposed by the donor groups (TX or DAF) which are the longest units.

In all molecules, the donor and the acceptor fragments are almost orthogonal with a twist angle (value in orange in Fig. 2) varying from $88^{\circ}$ for both STX-DAF and SPA-TXO ${ }_{2}, 89^{\circ}$ for STX$\mathbf{T X O}_{2}$ to $90^{\circ}$ for STX-DAF. This orthogonality between the donor and the acceptor moiety is at the origin of the absence of significant $\pi$-conjugation between them. Additionally, in the PA derivatives, the angle between the mean plane of the acridine units (indicated in purple in Fig. 2) and that of the attached phenyl is 85 and $88^{\circ}$ in SPA-TXO $\mathbf{S}_{2}$ and SPA-DAF respectively. This large angle indicates a second $\pi$-conjugation interruption at the nitrogen atom between the acridine unit and the phenyl group. As discussed below, these $\pi$-conjugation breaks are essential to keep the high $E_{\mathrm{T}}$ (see below).

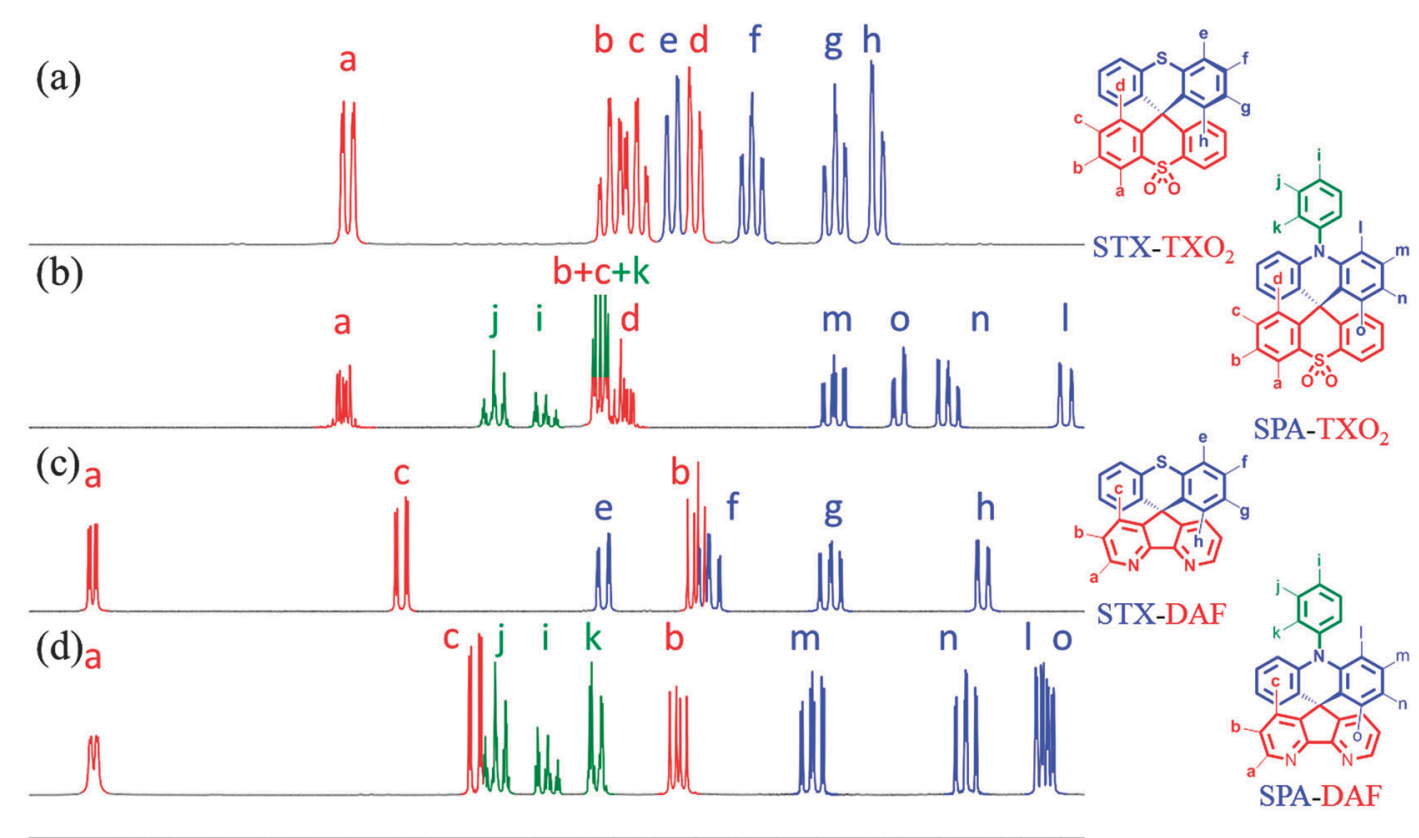

$\begin{array}{llllllllllllllllllllllllllllllllll}8.8 & 8.7 & 8.6 & 8.5 & 8.4 & 8.3 & 8.2 & 8.1 & 8.0 & 7.9 & 7.8 & 7.7 & 7.6 & 7.5 & 7.4 & 7.3 & 7.2 & 7.1 & 7.0 & 6.9 & 6.8 & 6.7 & 6.6 & 6.5 & 6.4 & 6 .\end{array}$

Fig. 1 Portion of the ${ }^{1} \mathrm{H}$ NMR spectra of (a) STX-TXO ${ }_{2}$, (b) SPA-TXO ${ }_{2}$, (c) STX-DAF and (d) SPA-DAF in $\mathrm{CD}_{2} \mathrm{Cl}_{2}$. 


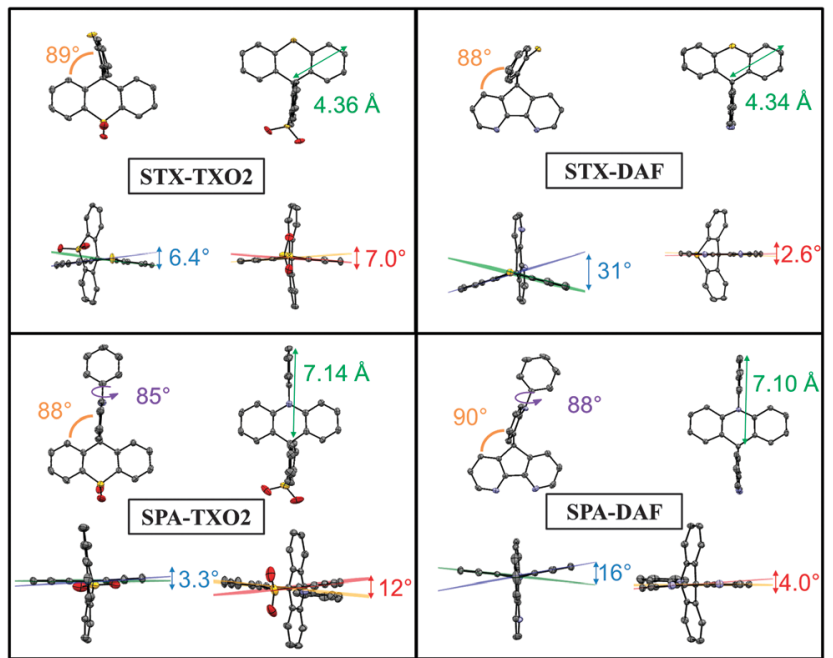

Fig. 2 Molecular structure from X-ray crystallography of STX-TXO left), STX-DAF (top right), SPA-TXO ${ }_{2}$ (bottom left), and SPA-DAF (bottom right) (ellipsoid probability at $50 \%$ level). Hydrogen atoms have been omitted for clarity.

For each aromatic unit, a torsional angle has been defined as the dihedral angle between the two external benzene rings of each unit (values in blue for the donor units and in red for the acceptor units in Fig. 2).

For the donor units, the TX torsion angles are impressively different depending on the acceptor core. Thus, a small angle of $6.4^{\circ}$ is recorded for STX-TXO $\mathbf{O}_{2}$ and a very large angle of $31^{\circ}$ is recorded for STX-DAF. Similarly, the torsion angles measured in the PA units are 5 times larger for SPA-DAF $\left(16^{\circ}\right)$ than for SPA-TXO ${ }_{2}\left(3.3^{\circ}\right)$. Thus, the donor fragments in SPA-DAF and STX-DAF are strongly more distorted than in their counterparts SPA-TXO ${ }_{2}$ and STX-TXO $\mathbf{O}_{2}$. The presence of the DAF unit within the dyes leads hence to a very distorted donor with large dihedral angles. This feature may be assigned to the packing forces induced by the presence of DAF. In addition and regardless of the acceptor, the PA units are always less distorted than the TX units surely due to the presence in PA of a pendant phenyl ring which provides a certain degree of rigidity.

For the acceptor units, the $\mathbf{T X O}_{2}$ torsion angle is $7^{\circ}$ for STX$\mathbf{T X O}_{2}$ and $12^{\circ}$ for SPA-TXO ${ }_{2}$ whereas this torsion angle is very weak in the case of the DAF unit: $2.6^{\circ}$ for STX-DAF, and $4.0^{\circ}$ for SPA-DAF. Thus, the very rigid DAF unit only allows very weak deformations due the presence of the $\mathrm{C}-\mathrm{C}$ bond in the $\alpha$ position of the nitrogen atoms. Such conformational locking is very similar to that observed for the fluorene unit. Oppositely, the presence of the sulphur atom linking the two phenyl groups in the $\mathbf{T} \mathbf{X O} \mathbf{O}_{\mathbf{2}}$ unit allows some deviations from planarity.

\section{Thermal properties}

Before any possible OLED applications and in order to confirm the interest of the present D-spiro-A design, the four compounds have been studied by thermogravimetric analysis (TGA) (Fig. 3) and differential scanning calorimetry (DSC) (see ESI $\dagger$ ).

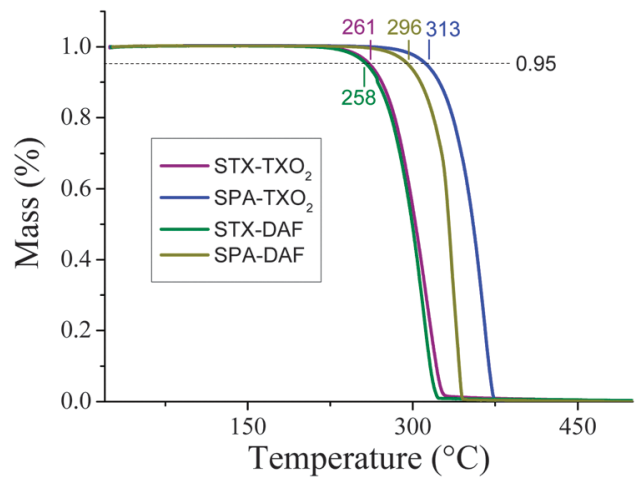

Fig. 3 TGA curves of STX-TXO ${ }_{2}$ (violet line), STX-DAF (green line), SPA-TXO (blue line) and SPA-DAF (yellow-green line).

The decomposition temperature, $T_{\mathrm{d}}$, is defined as the temperature corresponding to $5 \%$ of the mass loss. ${ }^{72}$ Herein, these temperatures are recorded as $261 / 258{ }^{\circ} \mathrm{C}$ for STX-TXO $\mathbf{S}_{2} / \mathbf{S T X}-\mathbf{D A F}$ and as $313 / 296{ }^{\circ} \mathrm{C}$ for $\mathbf{S P A}-\mathbf{T X O}_{2} / \mathbf{S P A}-\mathbf{D A F}$ respectively (Fig. 3). As a complete mass loss then occurs, we believe that this mass loss is attributed to a sublimation process as previously observed for other $\pi$-conjugated systems. ${ }^{24}$ Thus, the presence of the PA unit within the dye leads to a material with a higher $T_{\mathrm{d}}$ (by $c a .40 / 50^{\circ}$ ) than that obtained with the TX unit. DSC studies reveal no phase transition between room temperature and the decomposition of the molecules (see ESI $\dagger$ ). The rigid molecular structure of the two spiro-annulated fragments is at the origin of the interesting thermal properties of the four molecules.

\section{Electrochemical properties}

The electrochemical properties have been investigated by cyclic voltammetry (CV) in $\mathrm{CH}_{2} \mathrm{Cl}_{2}$ in oxidation and reduction (Fig. 4 and Table 1 , potentials given $v s$. SCE). In oxidation, the two TX derivatives present an irreversible oxidation with a maximum at $1.55 \mathrm{~V}$ for $\mathbf{S T X}-\mathbf{T X O}_{2}$ (violet line) and at $1.48 \mathrm{~V}$ for STX-DAF (green line). From their respective onset oxidation potentials $(1.42 / 1.34 \mathrm{~V})$, their HOMO energy levels were determined as $-5.79 /-5.74 \mathrm{eV}$ for $\mathbf{S T X}-\mathbf{T X O}_{2} / \mathbf{S T X}-\mathbf{D A F}$.

In the PA series, the two derivatives are oxidized at even lower anodic potentials and present one reversible oxidation wave with a maximum at $1.14 \mathrm{~V}$ for $\mathbf{S P A}-\mathbf{T X O}_{2}$ and two very close oxidation waves with maxima at $1.11 / 1.20 \mathrm{~V}$ for SPA-DAF. For SPA-DAF, recording $\mathrm{CV}$ up to the first oxidation wave only shows an irreversible oxidation wave indicating a high reactivity of the SPA-DAF ${ }^{\bullet+}$ species at the timescale of the CV (see Fig. S1 in the ESI $\dagger$ ). However, when reaching the second oxidation wave, an adsorption-like reduction peak is observed showing that the species formed during the two oxidation processes are strongly adsorbed at the electrode surface. From their onset potentials measured at 1.03/0.95 $\mathrm{V}$ for SPA-TXO ${ }_{2} /$ SPA-DAF respectively, the HOMO levels were calculated as $-5.42 \mathrm{eV}$ for $\mathbf{S P A}-\mathbf{T X O}_{2}$ and $-5.35 \mathrm{eV}$ for SPA-DAF.

In light of the electronic distribution of the HOMO (DFT calculations performed at the Gaussian 09 B3LYP/6-311+G(d,p) level of theory, Fig. 6), the first oxidations are assigned to the oxidation of the electron rich fragment, namely the TX unit in STX-TXO ${ }_{2} / \mathbf{S T X}-\mathbf{D A F}$ and to the PA core in SPA-TXO $\mathbf{S}_{2} / \mathbf{S P A - D A F}$. 

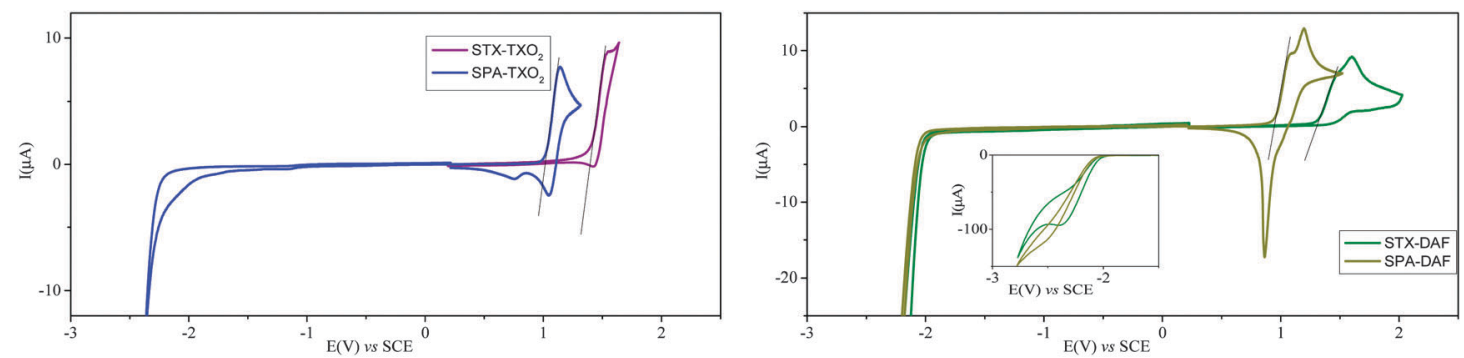

Fig. 4 Cyclic voltammetry $\left(100 \mathrm{mV} \mathrm{s}^{-1}\right)$ in $\mathrm{CH}_{2} \mathrm{Cl}_{2} /\left[\mathrm{Bu}_{4} \mathrm{~N}\right]\left[\mathrm{PF}_{6}\right] 0.2 \mathrm{M}$ of STX-TXO $\mathbf{S}_{2}$ (violet line) and SPA-TXO (blue line) (left) and of STX-DAF (green line), and SPA-DAF (yellow-green line) (right). Inset, $\mathrm{CV}$ recorded in reduction up to $-2.8 \mathrm{~V}$ for STX-DAF and SPA-DAF.

Table 1 Selected theoretical calculations, and electrochemical and thermal data of the four dyes

\begin{tabular}{|c|c|c|c|c|c|c|c|c|}
\hline & $E^{\mathrm{ox}}(\mathrm{V})$ & $E_{\text {onset }}^{\text {ox }}(\mathrm{V}) / \mathrm{HOMO}(\mathrm{eV})$ & $E^{\mathrm{red}}(\mathrm{V})$ & $E_{\text {onset }}^{\text {red }}(\mathrm{V}) / \mathrm{LUMO}(\mathrm{eV})$ & $\Delta E_{\mathrm{el}}(\mathrm{eV})$ & HOMO/LUMO & $\Delta E_{\text {theo }}(\mathrm{eV})$ & $\begin{array}{l}\text { Thermal } \\
\text { properties } \\
T_{\mathrm{d}}\left({ }^{\circ} \mathrm{C}\right)\end{array}$ \\
\hline SPA-TXO $_{2}$ & 1.14 & $1.02 /-5.42$ & - & $-2.40 /-2.00$ & 3.43 & $-5.57 /-1.44$ & 4.13 & 313 \\
\hline STX-DAF & $1.48 / 1.60$ & $1.30 /-5.70$ & -2.41 & $-2.06 /-2.34$ & 3.36 & $-5.87 /-1.87$ & 4.00 & 258 \\
\hline SPA-DAF & $1.11 / 1.20$ & $0.95 /-5.35$ & $\sim-2.5$ & $-2.09 /-2.31$ & 3.04 & $-5.49 /-1.72$ & 3.77 & 296 \\
\hline
\end{tabular}

In reduction (Fig. 4), the $\mathrm{TXO}_{2}$ derivatives are reduced at potential values close to that of the electrolytic medium reduction and their onset potentials are detected at $c a .-2.4 \mathrm{~V}$, with the LUMO levels lying hence around $-2.0 \mathrm{eV}$. The DAF derivatives are reduced at less negative potentials than those of the $\mathrm{TXO}_{2}$ derivatives and an irreversible reduction wave is observed (see inset in Fig. 4, right) with a maximum recorded at $-2.42 /-2.5 \mathrm{~V}$ for STX-DAF/SPA-DAF respectively. Thus, the LUMO levels of STX-DAF and SPA-DAF have been evaluated at $-2.34 /-2.31 \mathrm{eV}$, being $c a .0 .3 \mathrm{eV}$ lower than the LUMO levels of the $\mathrm{TXO}_{2}$ derivatives $(-2.0 \mathrm{eV})$. This feature clearly indicates the stronger electron accepting capability of DAF compared to that of $\mathrm{TXO}_{2}$ and its potential to decrease the LUMO level. Thus, SPA-DAF, possessing the strongest donor/acceptor combination, displays an electrochemical gap $\Delta E_{\text {elec }}$ of $3.04 \mathrm{eV}$, which is strongly more contracted than that of $\mathbf{S T X}-\mathbf{T X O} \mathbf{O}_{2}(3.79 \mathrm{eV})$, which possesses the weakest donor/acceptor combination (Fig. 5). STX-DAF and SPA$\mathbf{T X O}_{2}$ possess therefore intermediate values of 3.36 and $3.43 \mathrm{eV}$ respectively. For comparison purposes, structurally related 9, $9^{\prime}$-spirobifluorene $(\mathbf{S B F})^{72,73}$ possessing two spiro-connected fluorene units possesses a wide $\Delta E_{\text {elec }}$ of $4.05 \mathrm{eV}$ (HOMO: $-5.94 \mathrm{eV}$, LUMO: $-1.89 \mathrm{eV}),{ }^{33}$ which is widened by more than $1 \mathrm{eV}$ compared to that of SPA-DAF. Thus, compared to SBF, we can note that the TX unit leads to dyes with higher HOMO levels $(-5.94 \mathrm{eV}$ for SBF $v s$. $-5.70 /-5.79 \mathrm{eV}$ for STX-DAF/STX$\mathbf{T X O}_{2}$ ) and that the $\mathrm{TXO}_{2}$ unit leads to dyes with slightly lower LUMO levels $\left(-1.89 \mathrm{eV}\right.$ for SBF $v s .-2.0 \mathrm{eV}$ for both STX-TXO ${ }_{2}$ and $\mathbf{S P A}-\mathbf{T X O}_{2}$ ). The effect of these fragments on the molecular orbital energy levels are hence relatively weak compared to those of fluorene. Oppositely, the PA/DAF units lead to a strong increase/decrease of the HOMO/LUMO energy levels compared to SBF. Thus, the PA/DAF combination seems to be the more attractive leading to the smallest gap, $3.04 \mathrm{eV}$, in the series

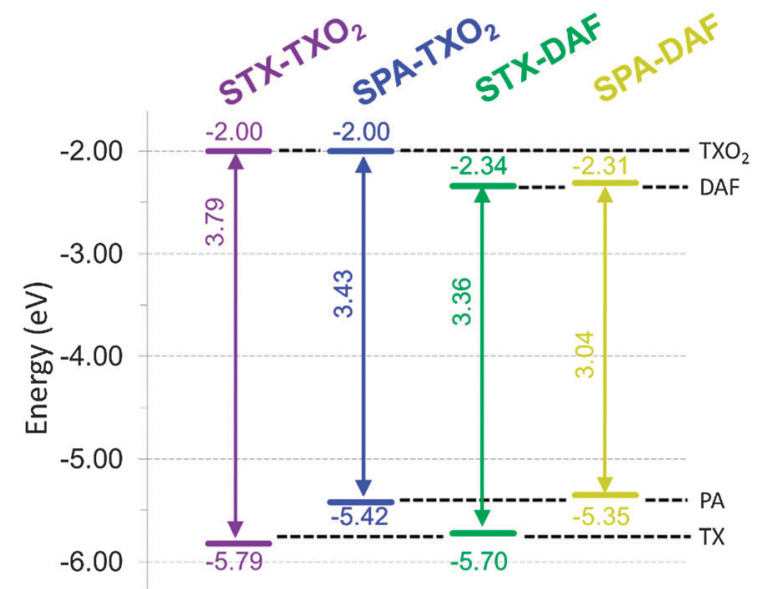

Fig. $5 \mathrm{HOMO/LUMO}$ energy levels and $\Delta E_{\mathrm{el}}(\mathrm{eV})$ obtained from electrochemical investigations.

whereas the $\mathrm{TX} / \mathrm{TXO}_{2}$ combination leads to the widest gap in the series, $3.79 \mathrm{eV}$, highlighting not only the efficiency of the present design to tune the electronic properties of spiro-connected compounds but also the importance of the chosen donor/acceptor combination.

Compared to previously reported structurally related PA compounds bridged by spiroanthracenone (HOMO/LUMO: $-5.50 /-1.90 \mathrm{eV}$ ) or by two phenyls units (HOMO/LUMO: $-5.42 /-1.74 \mathrm{eV}$ ), ${ }^{42}$ SPA-TXO $_{2}$ and SPA-DAF (HOMO: -5.42 and $-5.35 \mathrm{eV}$ respectively) have (i) a very similar HOMO energy level, due to the presence of the PA unit, but (ii) a lower LUMO energy level (LUMO: $-2 \mathrm{eV}$ and $-2.31 \mathrm{eV}$ ) due to the presence of either the $\mathrm{TXO}_{2}$ or the DAF unit instead of the anthracenone core. Thus, the present design allows selective tuning of the LUMO energy level without changing that of the HOMO. 


\section{Theoretical calculations}

Geometry optimization of the four dyes in the singlet and triplet states was performed using density functional theory (DFT) at the Gaussian 09 B3LYP/6-311+G(d,p) level of theory. All the results are reported in Table 1 and in Fig. 6. The electronic distribution and the energy levels of the HOMOs and LUMOs (and the corresponding energy gaps, $\Delta E_{\text {theo }}$ ) have been determined on optimized geometries. The same tendency is observed between the HOMO/LUMO values determined by CV and those obtained by theoretical calculations. The HOMO levels (calculated at -5.49 and $-5.57 \mathrm{eV}$ ) of SPA-DAF and SPA-TXO $\mathbf{S}_{2}$ are exclusively centred on the PA units (Fig. 6) in accordance with an electron transfer centred on this unit as suggested above in the electrochemical part. One can note that there is no electron density on the pendant $N$-phenyl group meaning that the electronic properties of the PA unit are independent of this pendant phenyl. The HOMOs of STX-TXO $\mathbf{S}_{2}$ and STX-DAF are mainly localized on the
TX unit, leading to deeper HOMO energy levels (-6.03 and $-5.87 \mathrm{eV}$ ) than those of the PA derivatives.

The calculated LUMO levels of STX-DAF and SPA-DAF are lower in energy $(-1.87$ and $-1.72 \mathrm{eV}$ respectively) than those of STX-TXO ${ }_{2}$ and $\mathbf{S P A}-\mathbf{T X O}_{2}(-1.59$ and $-1.44 \mathrm{eV})$ clearly showing the stronger electron accepting nature of the DAF unit compared to that of the $\mathrm{TXO}_{2}$ unit. For the two DAF derivatives, the LUMO level is localized on the DAF fragment (in accordance with a first electrochemical reduction centred on this fragment, see above) and is separated by more than $0.6 \mathrm{eV}$ from the LUMO+1 level. However, for the $\mathrm{TXO}_{2}$ derivatives, the situation

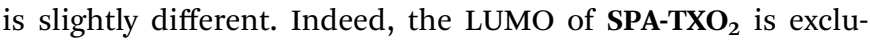
sively spread out on the $\mathrm{TXO}_{2}$ core whereas that of STX-TXO seems to be not only spread out on the $\mathrm{TXO}_{2}$ core but also on the central TX unit. For both $\mathrm{TXO}_{2}$ derivatives, the gap between the LUMO and the LUMO+1 is less than $0.1 \mathrm{eV}(0.05 / 0.1 \mathrm{eV}$ for STX-TXO $\mathbf{O}_{2} / \mathbf{S P A}^{-\mathbf{T X O}_{2}}$ ) indicating some possible mixing of the
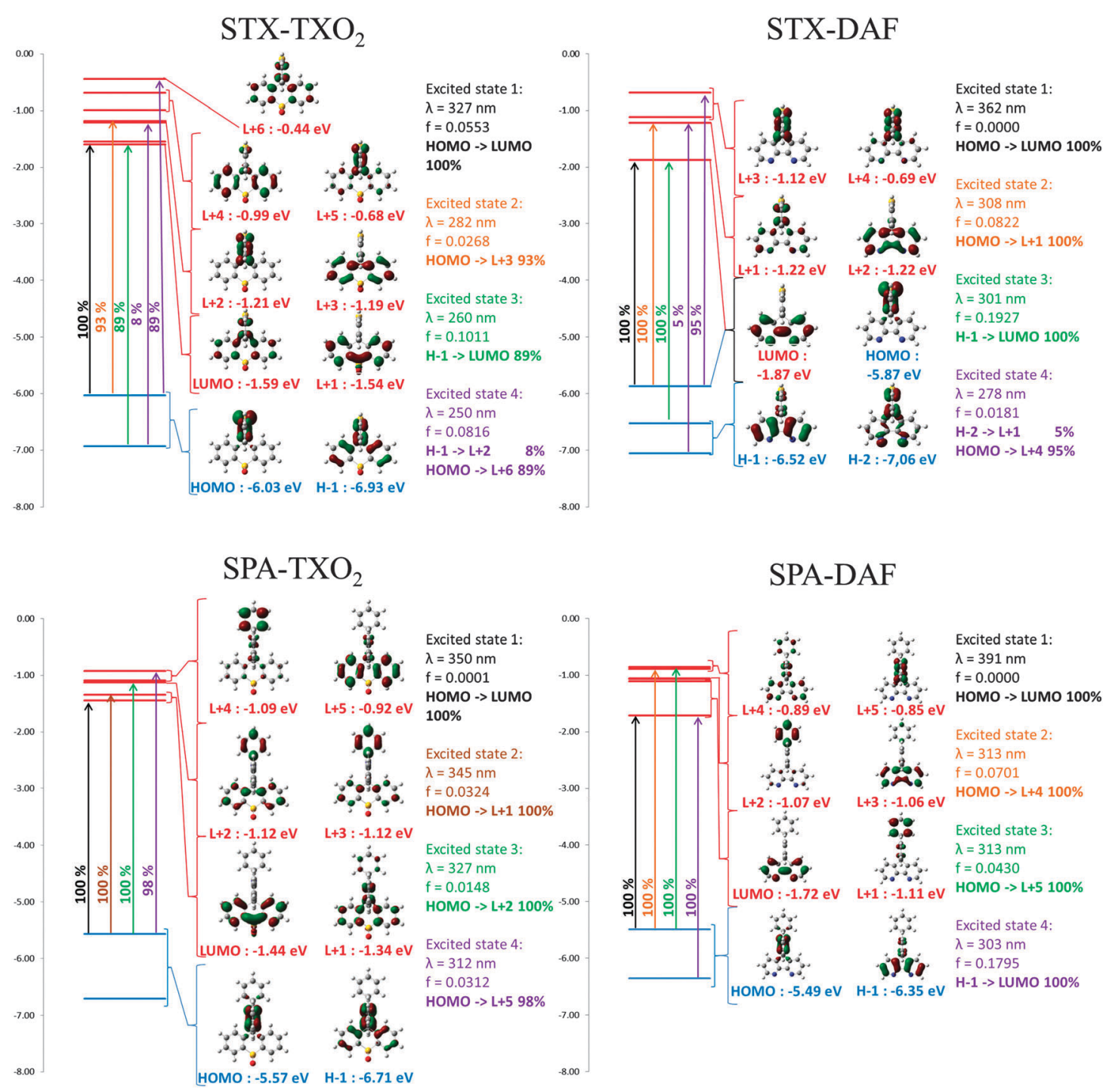

Fig. 6 Calculated frontier molecular orbitals by DFT B3LYP/6-311+G(d,p) and the first four calculated electronic transitions by TD-DFT after geometry optimization with DFT B3LYP/6-311+G(d,p), shown with an isovalue of $0.04\left[\mathrm{e} \mathrm{bohr}^{-3}\right]^{1 / 2}$. 
LUMO and LUMO+1 orbitals. In conclusion the electronic separation between the donor (HOMO) and the acceptor unit (LUMO), the key point in host design, is clearly more efficient for the DAF derivatives than for the $\mathrm{TXO}_{2}$ derivatives. The calculated energy gaps, $\Delta E_{\text {theo }}$, follow the same trend as the electrochemical ones with the lowest gap calculated for SPA-DAF $(3.77 \mathrm{eV})$ and the highest recorded for STX-TXO $2(4.44 \mathrm{eV})$.

\section{Absorption spectroscopy}

The UV-visible absorption spectra of the four D-spiro-A dyes, recorded in cyclohexane, are presented in Fig. 7 and their main characteristics are summarized in Table 2. The four compounds present different absorption spectra with three or four absorption bands with low absorption coefficients (between $5 \times 10^{3}$ to $20 \times 10^{3} \mathrm{~L} \mathrm{~mol}^{-1} \mathrm{~cm}^{-1}$ ) in the range $260-350 \mathrm{~nm}$. This is fully consistent with the presence of small and weakly conjugated units.

The absorption spectra of the two $\mathbf{T X \mathbf { O } _ { 2 }}$ derivatives (Fig. 7, left) are similar in the high energy range (maxima at $274 / 281 \mathrm{~nm}$ for STX-TXO ${ }_{2}$ and at $273 / 280 \mathrm{~nm}$ for SPA-TXO $\mathbf{S}_{2}$ ) indicating that these two absorption bands may be associated to the $\mathrm{TXO}_{2}$ fragment. A series of previously reported $\mathrm{TXO}_{2}$ derivatives spiro-linked to 2,7-triphenylamine-fluorene or to 2,7- $\mathrm{N}$-phenylcarbazole fluorene also present absorption bands of the $\mathrm{TXO}_{2}$ units close to $300 \mathrm{~nm}^{51}$

In the lowest energy range, the two spectra are nevertheless different with one broad band centred at $309 \mathrm{~nm}$ for STX-TXO and two broad bands centred at 297 and $323 \mathrm{~nm}$ for SPA-TXO $\mathbf{S}_{2}$. The band at $309 \mathrm{~nm}$ may therefore be associated to TX and the two bands at 297 and $323 \mathrm{~nm}$ to PA. The absorption of TX has been previously reported and possesses a maximum centred at
$266 \mathrm{~nm}$ in ethanol. ${ }^{74}$ Thus, there is a red-shift of $43 \mathrm{~nm}$ between the absorption of TX and that of the spiro-bridged TX recorded herein for STX-TXO $\mathbf{S}_{2}$. A similar red-shift of $32 \mathrm{~nm}$ has been reported for spiro-connected TX (bridged with 2,7-triphenylamine-fluorene, $\lambda_{\text {max }}: 298 \mathrm{~nm}$ in $\mathrm{CH}_{2} \mathrm{Cl}_{2}$ ). ${ }^{51}$ This red shift is due to the different influence of a methylene bridge and of a spiro-aromatic bridge on the TX core. Interestingly, the absorption spectra of structurally related compounds built on the spiro-connection of PA units with anthracenone ${ }^{41}$ present the same profile as that presented herein for SPA-TXO $\mathbf{O}_{2}$ with two absorption bands with maxima at $300 / 320 \mathrm{~nm}^{41}$

The two DAF derivatives (Fig. 7, right) present similar absorption spectra at lower energy, with the absorption being however broader for SPA-DAF than for STX-DAF. The two main absorption bands centred at 306/307 and $319 \mathrm{~nm}$ may be assigned to the absorption of the DAF core in accordance with the literature data. ${ }^{64,66,69,75}$ In addition, we have shown above that the band at $309 \mathrm{~nm}$ in $\mathbf{S T X}-\mathbf{T X O} \mathbf{O}_{2}$ was assigned to the TX absorption. Thus, in STX-DAF, there is a clear superimposition of the absorptions of TX and DAF cores leading to a large band at $307 \mathrm{~nm}$, being relatively more intense than that at $319 \mathrm{~nm}$. Similarly, in the case of SPA-DAF, there is an overlap between the PA and DAF fragments, with the shoulder observed above $327 \mathrm{~nm}$ being surely due to the absorption of the PA core. Finally, it should be stressed that higher absorption coefficients are obtained for SPA-DAF than for STX-DAF (SPA-DAF: $\varepsilon_{319} \mathrm{~nm}=$ $20.4 \times 10^{3} \mathrm{~L} \mathrm{~mol}^{-1} \mathrm{~cm}^{-1}$ and $\varepsilon_{306 \mathrm{~nm}}=16.4 \times 10^{3} \mathrm{~L} \mathrm{~mol}^{-1} \mathrm{~cm}^{-1}$, STX-DAF: $\varepsilon_{319 \mathrm{~nm}}=12.1 \times 10^{3} \mathrm{~L} \mathrm{~mol}^{-1} \mathrm{~cm}^{-1}$ and $\varepsilon_{307 \mathrm{~nm}}=12.9 \times$ $\left.10^{3} \mathrm{~L} \mathrm{~mol}^{-1} \mathrm{~cm}^{-1}\right)$.

The calculated absorption spectra from TD-DFT (Fig. 6) show that, except for STX-TXO $\mathbf{O}_{2}$, the HOMO/LUMO transitions
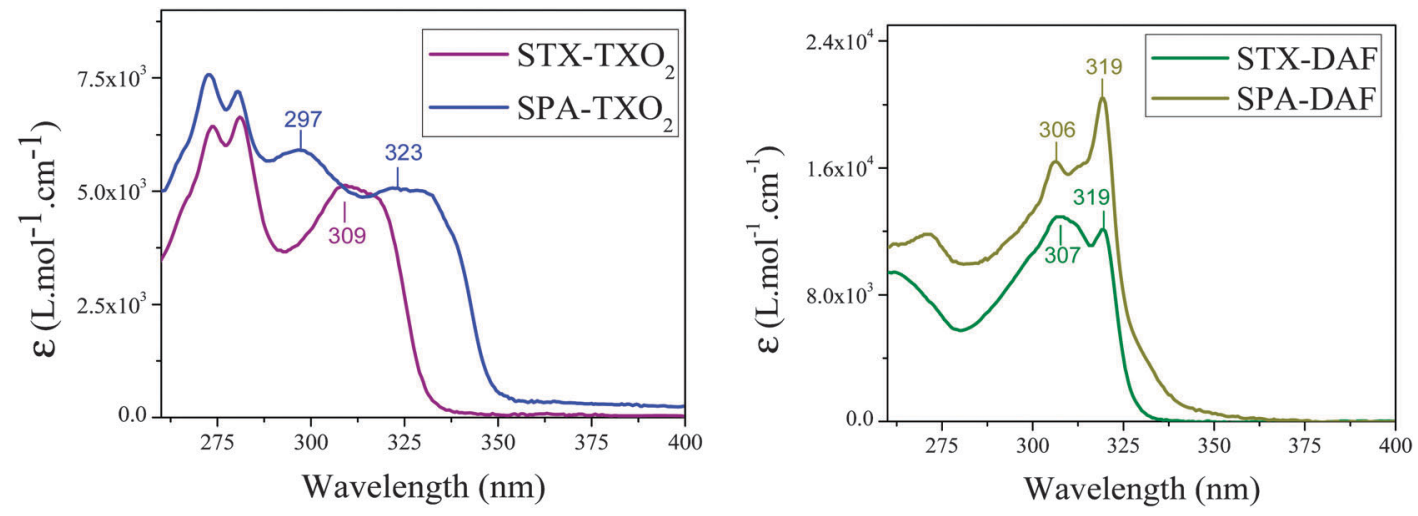

Fig. 7 Absorption spectra of the four dyes in cyclohexane.

Table 2 Photophysical properties of the four dyes

\begin{tabular}{|c|c|c|c|c|c|c|c|c|}
\hline & $\lambda_{\mathrm{abs}}(\mathrm{nm})\left[10^{3} \varepsilon\left(\mathrm{L} \mathrm{mol}^{-1} \mathrm{~cm}^{-1}\right)\right]$ & $\begin{array}{l}\Delta E_{\mathrm{opt}}{ }^{b} \\
(\mathrm{eV})\end{array}$ & $\begin{array}{l}\lambda_{\mathrm{em}}{ }^{b} \\
(\mathrm{~nm})\end{array}$ & $\begin{array}{l}\lambda_{\mathrm{em}}{ }^{c} \\
(\mathrm{~nm})\end{array}$ & $\begin{array}{l}\Delta \nu^{b} \\
\left(\mathrm{~cm}^{-1} / \mathrm{eV}\right)\end{array}$ & $\begin{array}{l}\Phi^{b}(\%) \\
{\left[\lambda_{\text {exc }}(\mathrm{nm})\right]}\end{array}$ & $\begin{array}{l}E_{\mathrm{T}}{ }^{d} \\
(\mathrm{eV})\end{array}$ & $\begin{array}{l}\Delta S-T^{e} \\
(\mathrm{eV})\end{array}$ \\
\hline $\mathrm{STX}^{-\mathrm{TXO}_{2}}$ & 309 (5.1); $281^{a}(6.6) ; 274(6.4)$ & 3.73 & 338 & 362 & $2780 / 0.34$ & $0.8[308]$ & 3.06 & 0.61 \\
\hline SPA-TXO $_{2}$ & 323 (5.1); 297 (5.9); $280(7.2) ; 273^{a}(7.6)$ & 3.54 & 350 & 371 & $2390 / 0.30$ & $4.1[323]$ & 3.08 & 0.46 \\
\hline SPA-DAF & $330(\mathrm{sh}) ; 319^{a}(20.4) ; 306(16.4) ; 271$ (11.8) & 3.64 & 388 & 420 & $5570 / 0.69$ & $0.1[319]$ & 2.98 & 0.22 \\
\hline
\end{tabular}


are theoretically forbidden (oscillator strength: 0.000 ). This is a crucial point, which finds its origin in the spatial separation of the HOMO and LUMO levels leading to through space forbidden transitions. The calculated energy of this HOMO/LUMO transition varies from $327 \mathrm{~nm}$ for STX-TXO $\mathbf{O}_{2}$ to $391 \mathrm{~nm}$ for SPA-DAF when going from weak donor/acceptor units ( $\mathrm{TX}$ and $\mathrm{TXO}_{2}$ ) to strong ones (PA and DAF). In STX-TXO $\mathbf{S}_{2}$, as the electronic densities of the HOMO and the LUMO allow some orbital overlap, the oscillator strength of the HOMO/LUMO transition is slightly higher (0.0553) and the transition is weakly allowed. Thus, in the case of the DAF derivatives SPA-DAF and STX-DAF, the theoretical HOMO/ LUMO transitions (391 and $362 \mathrm{~nm}$ respectively) are not detectable experimentally in their corresponding absorption spectra. Similarly, no band at $350 \mathrm{~nm}$ is observed for SPA-TXO $\mathbf{S}_{2}$. Finally, the HOMO/LUMO theoretical transition calculated at $327 \mathrm{~nm}$ for STX-TXO $\mathbf{O}_{2}$ would be overlapped with the other absorptions bands.

Regarding the other transitions, one can note that a high oscillator strength $(f>0.17)$ transition is observed for both DAF derivatives. Indeed for both STX-DAF and SPA-DAF, HOMO-1/LUMO transitions between the DAF units are detected at $301 \mathrm{~nm}$ and $303 \mathrm{~nm}$ respectively. These oscillator strengths are in accordance with the high $\varepsilon$ value recorded for these molecules (see above). For $\mathrm{TXO}_{2}$ derivatives, the situation

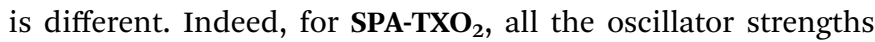
are very low $(f<0.033)$, with the more intense transitions being observed at $345 \mathrm{~nm}$ between the HOMO and LUMO+1 ( $f=0.0324$ ) and at $312 \mathrm{~nm}$ between the HOMO and LUMO+5 $(f=0.0312)$. The transitions all involve PA units. In the case of STX-TXO $\mathbf{O}_{2}$, all the oscillator strengths are also very low except for a HOMO-1/LUMO transition $(f=0.1011)$ with both orbitals involving the TX and $\mathrm{TXO}_{2}$ molecular fragments.

Optical gaps, $\Delta E_{\mathrm{opt}}$, have been evaluated from the onset of the last absorption band, varying from $3.54 \mathrm{eV}$ to $3.79 \mathrm{eV}$ (STX-TXO ${ }_{2}: 3.73 \mathrm{eV}$, SPA-TXO $_{2}: 3.54 \mathrm{eV}$, STX-DAF: $3.79 \mathrm{eV}$ and SPA-DAF: $3.64 \mathrm{eV}$ ). Thus, one can note that $\mathbf{T X O}_{2}$ derivatives present a $\Delta E_{\text {opt }}$ in accordance with the electrochemical gap $\Delta E_{\mathrm{el}}$, which is not the case for DAF derivatives (Table 1). Indeed, STX-DAF and SPA-DAF possess a $\Delta E_{\text {opt }}$ strongly wider than their corresponding $\Delta E_{\text {el }}$ (see Tables 1 and 2). Indeed and as exposed above, all molecules possess a theoretical forbidden through space $\mathrm{HOMO} / \mathrm{LUMO}$ transition, calculated at a higher energy for $\mathrm{TXO}_{2}$ derivatives (327 and $350 \mathrm{~nm}$ ) than for DAF derivatives (362 and $391 \mathrm{~nm}$ ). $\Delta E_{\text {opt }}$ should hence be determined with this absorption band. Thus, in the case of $\mathrm{TXO}_{2}$ derivatives, this hypothetical transition would be overlapped in the tail of the large absorption band at $323 \mathrm{~nm}\left(\right.$ SPA-TXO $_{2}$ ) and $309 \mathrm{~nm}$ (STX$\mathbf{T X O}_{2}$ ) whereas in the case of DAF derivatives this band would be found at a lower energy (362 and $391 \mathrm{~nm}$ ). Since $\Delta E_{\text {opt }}$ does not correspond for DAF derivatives to the energy difference between the HOMO and LUMO, this feature explains the difference observed between $\Delta E_{\mathrm{opt}}$ and $\Delta E_{\mathrm{el}}$. As DAF derivatives present an almost identical $\Delta E_{\text {opt }}$ (3.79 and $3.64 \mathrm{eV}$ ), for both compounds, the transition involved is surely a HOMO-1/LUMO transition implying only the DAF units (Fig. 6).

\section{Emission spectroscopy}

TX derivatives present structureless emission spectra with maxima recorded at $338 \mathrm{~nm}$ for $\mathbf{S T X}-\mathbf{T X O}_{2}$ and at $348 \mathrm{~nm}$ for STX-DAF (Fig. 8, left). The literature reports the emission of 4,5diazaspirobifluorene ${ }^{66}$ at $350 \mathrm{~nm}$ (in THF) in accordance with that of STX-DAF, highlighting the weak influence of the spiroconnected unit (fluorene in diazaspirobifluorene and thioxanthene in STX-DAF) on the DAF core. The emissions of the PA derivatives also appear structureless and are red-shifted compared to those of the TX derivatives $\left(\lambda_{\max }=348 / 350 \mathrm{~nm}\right.$ for $\mathbf{S P A}-\mathbf{T X O}_{2}$, and $\lambda_{\text {max }}=388 \mathrm{~nm}$ for SPA-DAF). Thus, one can observe a red-shift of the emission maxima (and hence a gap contraction) as the donor and acceptor strength increases. It is important to mention that the emission of all compounds fits well with the energy of the HOMO/LUMO transition calculated by TD-DFT (STX-TXO $\mathbf{2}_{2}: 327 \mathrm{~nm}$, STX-DAF: $350 \mathrm{~nm}$, SPA-TXO $\mathbf{S}_{2}: 362 \mathrm{~nm}$, and SPA-DAF: $391 \mathrm{~nm}$, see above). This clearly confirms the above mentioned assignment of a through space electronic transfer depending on the electrochemical HOMO/LUMO gap. The emission of the four dyes is hence due to a photoinduced intramolecular charge transfer (ICT) between the donor and the acceptor in the excited state (see the below solvatochromic experiments). The greater the donor-acceptor strength, the more contracted the gap and the more red-shifted the emission. Another signature of a through space electronic transfer is the very low quantum yield (QY) translating the very weak probability of this transition.
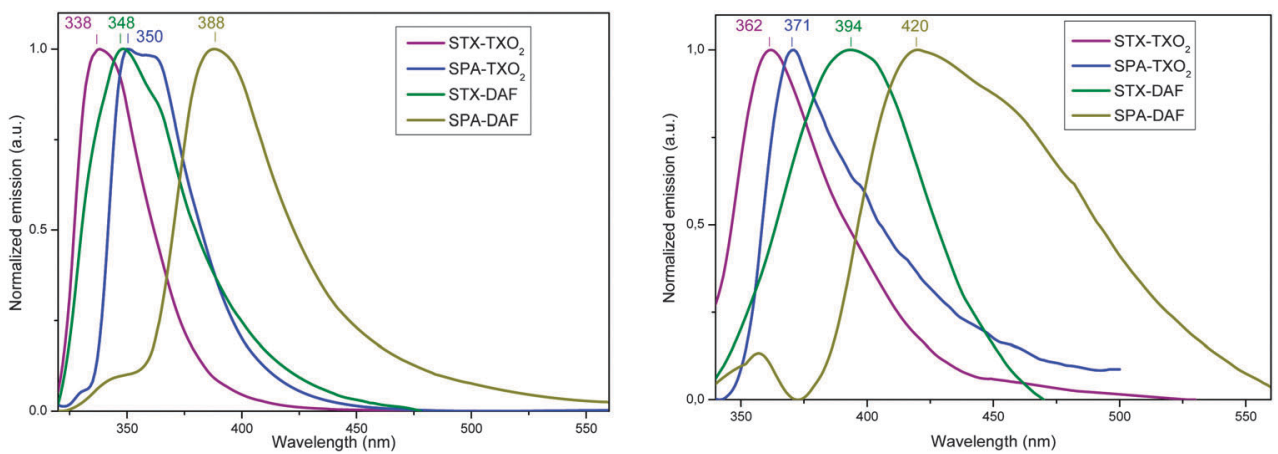

Fig. 8 Emission spectra of the four dyes in cyclohexane (left) (concentration $\sim 10^{-3} \mathrm{M}$ ) and in the solid state (right) (thin film, deposited on a sapphire plate from $50 \mu \mathrm{L}$ of a $10 \mathrm{~g} \mathrm{~L}^{-1}$ solution). 
In the present case, the QYs are indeed very low varying from $\mathbf{0 . 1} \%$ for the two DAF derivatives to $0.8 / 4.1 \%$ for $\mathbf{S P A}-\mathbf{T X O}_{2} /$ STX-TXO ${ }_{2}$ respectively, in perfect accordance with our above mentioned conclusions. In addition, it should be noted that another emission of low intensity is detected at high energy (ca. 330/350 nm) for SPA-DAF, which can be tentatively assigned to an emission induced by the fragments (PA or DAF) alone corresponding to a locally excited state or to an emission from a higher excited state. Indeed, for comparison purposes, the emission of triphenylamine is reported at $358 \mathrm{~nm}$ (in $\mathrm{THF})^{76}$ and that of $N$-phenyl-carbazole at $347 \mathrm{~nm}$ (in THF) ${ }^{76}$ in accordance with the tiny band detected for SPA-DAF.

Regarding the solid state fluorescence properties (Fig. 8, right), the emission spectra appear broader and red-shifted (from 21 to $46 \mathrm{~nm}$ ) compared to the solution ones. This red-shift is assigned not only to the different dielectric constants between the two environments (liquid vs. solid) but also to the existence of intermolecular interactions in the solid state which may appear surprising due to the 3D geometry induced by the spiro carbon.

Solvatochromic experiments allow a deeper understanding of the photophysical properties of the dyes through the determination of the polarity of the excited states (Table 3 and Fig. 9). First, as the absorption spectra do not differ much as a function of the polarity, the characteristics of the ground and FranckCondon excited states are very similar (see the ESI $\dagger$ ). Oppositely, the fluorescence spectra show an intense solvatochromic effect. Indeed, the emission maxima of all the fluorophores are redshifted with the increased polarity of the solvent (from cyclohexane to acetonitrile, see Fig. 9). This shift is of 58, 93, 110 and $111 \mathrm{~nm}$ for STX-TXO $_{2}$, STX-DAF, SPA-TXO ${ }_{2}$ and SPA-DAF respectively.

Table 3 Photophysical properties of the four dyes as a function of the polarity of the solvents

\begin{tabular}{|c|c|c|c|c|c|c|}
\hline & \multicolumn{5}{|c|}{$\underline{\lambda_{\mathrm{abs}}(\mathrm{nm}) / \lambda_{\mathrm{em}}(\mathrm{nm}) / \Phi(\%)\left[\lambda_{\mathrm{exc}}(\mathrm{nm})\right]}$} & \multirow[b]{2}{*}{$\Delta \mu / \mu(\mathrm{S} 1) / \mu(\mathrm{S} 0)^{a}$ (D) } \\
\hline & Cyclohexane & Toluene & Chloroform & Ethyl acetate & Acetonitrile & \\
\hline STX-TXO $_{2}$ & $309 / 338 / 0.8$ [309] & $311 / 348 / 0.7$ [309] & $312 / 354 / 0.7[312]$ & $310 / 353 / 0.9[309]$ & $310 / 396 / 1.1[310]$ & $13.4 / 18.2 / 4.8$ \\
\hline SPA-TXO & $324 / 350 / 4.1[323]$ & $326 / 382 / 2.3[325]$ & $328 / 421 / 1.2[328]$ & $326 / 410 / 1.7[326]$ & $300 / 460 / 1.4[323]$ & $32.6 / 40.1 / 7.5$ \\
\hline STX-DAF & $319 / 348 / 0.1[319]$ & $322 / 391 / 0.1[321]$ & $322 / 398 / 0.1[322]$ & $320 / 395 / 0.1[319]$ & $320 / 441 / 0.1[319]$ & $14.3 / 17.4 / 3.1$ \\
\hline SPA-DAF & $319 / 388 / 0.1[319]$ & $321 / 429 / 0.1[321]$ & $323 / 440 / 0.2[332]$ & $320 / 465 / 0.1[319]$ & $321 / 499 / 0.5[320]$ & $29.2 / 35.4 / 6.2$ \\
\hline
\end{tabular}

${ }^{a} \mu$ (S0) has been obtained through DFT calculations, and $\Delta \mu$ has been obtained using the Lippert-Mataga formalism, $\Delta \mu=\mu(\mathrm{S} 1)-\mu(\mathrm{S} 0)$.
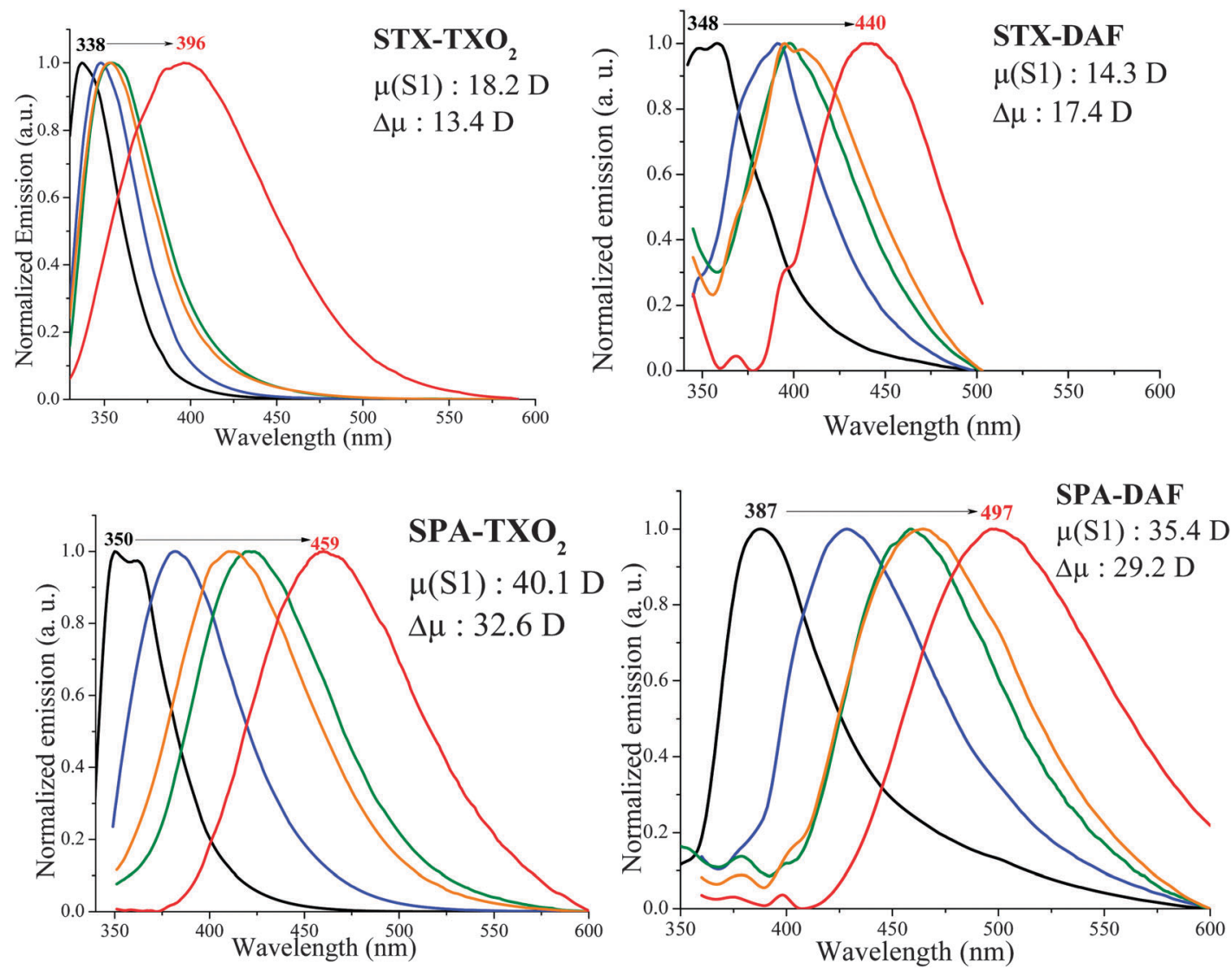

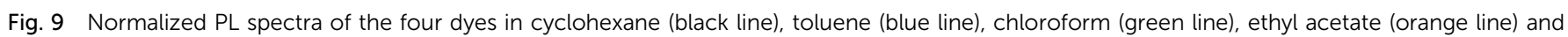
acetonitrile (red line). 


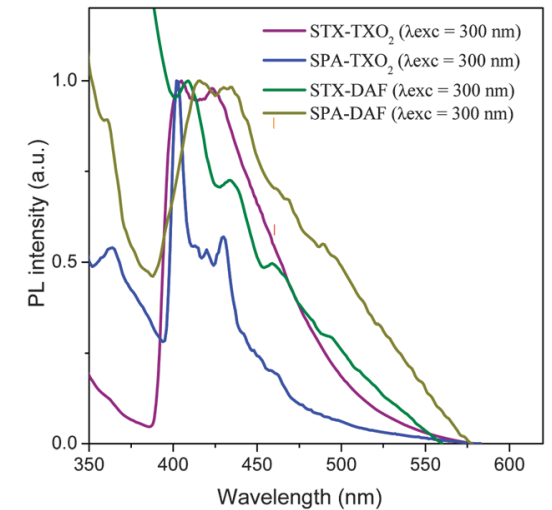

Fig. 10 Emission spectra of the four dyes recorded at $77 \mathrm{~K}$ in frozen methylcyclohexane/2-methylpentane (1/1).

The large bathochromic shift of the fluorescence emission is the consequence of the stabilization of the intramolecular charge transfer (ICT) excited state relative to the ground state, leading to an energy gap contraction. This is caused by dipole-dipole interactions between the dyes and polar solvent molecules and hence there is a photoinduced ICT between the donor and the acceptor. $\Delta \mu$ values of $13.4 \mathrm{D}$ (STX-TXO $\left.{ }_{2}\right), 32.6 \mathrm{D}\left(\right.$ SPA-TXO $\left._{2}\right)$, 14.3 D (STX-DAF) and 29.2 D (SPA-DAF) have been evaluated using the Lippert-Mataga formalism (the dipole moments at the ground state obtained through DFT calculations were: 4.8, 7.5, 3.1 and 6.2 D for STX-TXO ${ }_{2}$, SPA-TXO $_{2}$, STX-DAF and SPA-DAF, see details of the calculations in the ESI $\dagger)$. We note that the PA derivatives (SPA-TXO ${ }_{2}, \Delta \mu: 32.6 \mathrm{D}$ and SPA-DAF, $\Delta \mu: 29.2 \mathrm{D}$ ) lead to $\Delta \mu$ values twice as large as those calculated for the TX derivatives (STX-TXO ${ }_{2}, \Delta \mu: 13.4 \mathrm{D}$ and STX-DAF, $\Delta \mu$ : $14.3 \mathrm{D}$ ). This reflects the stronger electron donating ability of PA compared to TX and hence the stronger ICT induced.

Phosphorescence of the four dyes was studied at $77 \mathrm{~K}$ in frozen methylcyclohexane/2-methylpentane (1/1) (Fig. 10). $\mathrm{TXO}_{2}$ derivatives present a first phosphorescent transition at $405 / 402 \mathrm{~nm}$ corresponding to an $E_{\mathrm{T}}$ of 3.06 and $3.08 \mathrm{eV}$ for STX$\mathbf{T X O}_{2}$ and SPA-TXO ${ }_{2}$ respectively. For the DAF derivatives, a first phosphorescence contribution is observed at $409 \mathrm{~nm}\left(E_{\mathrm{T}}: 3.03 \mathrm{eV}\right)$ for STX-DAF and at $416 \mathrm{~nm}\left(E_{\mathrm{T}}: 2.98 \mathrm{eV}\right)$ for SPA-DAF. In light of these results, the spin density of the triplet state of the four molecules is probably located on their corresponding acceptor unit. This is a key point to be considered for the future design of structurally related host materials with a D-spiro-A architecture. The four compounds present hence a very high $E_{\mathrm{T}}(3.03 \pm 0.05 \mathrm{eV})$, enabling their use as a host for blue dopants.

\section{Phosphorescent OLEDs}

Sky-blue (FIrpic) PhOLEDs were fabricated and characterised using the four host materials. The device configuration was ITO/ CuPc $(10 \mathrm{~nm}) / \mathrm{NPB}(40 \mathrm{~nm}) / \mathrm{TCTA}(10 \mathrm{~nm}) / \mathrm{EML}:$ FIrpic $(20 \mathrm{~nm}) /$ TPBi $(40 \mathrm{~nm}) / \mathrm{LiF}(1.2 \mathrm{~nm}) / \mathrm{Al}(100 \mathrm{~nm})$. ITO is used as the anode, CuPc (copper phthalocyanine) is the hole injecting layer, NPB ( $N, N^{\prime}$-di(1-naphthyl)- $N, N^{\prime}$-diphenyl-[1,10-biphenyl]-4,4'-diamine) is the hole transporting layer, TCTA $\left(4,4^{\prime}, 4^{\prime \prime}\right.$-tris(carbazol-9-yl)triphenylamine) is the electron/exciton blocking layer,
TPBI (1,3,5-tris(1-phenyl-1 $H$-benzimidazol-2-yl)benzene) is both the electron transporting layer and the hole blocking layer and a thin film of lithium fluoride covered with aluminium is the cathode. The device architecture and the relative energy levels of the successive layers can be found in our previous work. ${ }^{32,33}$

The four dyes were used as hosts for the sky-blue dopant FIrpic $\left(E_{\mathrm{T}}: 2.62 \mathrm{eV}\right) .^{77}$ Different FIrpic concentrations were tested and the best performances were obtained with a FIrpic $20 \%$ doped EML. Those performances are reported in Fig. 11 and the main device characteristics are summarized in Table 4. The more efficient blue PhOLEDs were based on SPA-DAF, STXDAF and $\mathbf{S P A - T X O _ { 2 }}$, whereas devices using STX-TXO $_{2}$ as the host were clearly less efficient.

In the $\mathrm{TXO}_{2}$ family, PhOLEDs using $\mathbf{S P A}-\mathbf{T X O}_{2}$ as the host reach a high $\mathrm{EQE}$ of $10.6 \%$ (at $10 \mathrm{~mA} \mathrm{~cm} \mathrm{~cm}^{-2}$ ), whereas those using $\mathbf{S T X - T X O _ { 2 }}$ as the host are much less efficient displaying a very low EQE of $1.9 \%$. The corresponding luminous (CE) and power (PE) efficiencies are recorded at $27.7 \mathrm{~cd} \mathrm{~A}^{-1}$ and at $14.7 \mathrm{~lm} \mathrm{~W}^{-1}$ for SPA-TXO ${ }_{2}$ and at $4 \mathrm{~cd} \mathrm{~A}^{-1}$ and at $1.2 \mathrm{~lm} \mathrm{~W}^{-1}$ for STX-TXO ${ }_{2}$. The devices incorporating DAF derivatives do not display such differences as both display an interesting performance at $10 \mathrm{~mA} \mathrm{~cm}{ }^{-2}$ with an EQE of $8 \%\left(\mathrm{CE}=22 \mathrm{~cd} \mathrm{~A}^{-1}\right.$ and $\left.\mathrm{PE}=10.4 \mathrm{~lm} \mathrm{~W}{ }^{-1}\right)$ and $10.2 \%\left(\mathrm{CE}=24.3 \mathrm{~cd} \mathrm{~A}^{-1}\right.$ and $\left.\mathrm{PE}=14 \mathrm{~lm} \mathrm{~W}^{-1}\right)$ for STX-DAF and SPA-DAF respectively.

From these blue PhOLED performances, several conclusions can be drawn. First, it is clear that the incorporation of PA units within the structure is strongly correlated to the high performance of the PhOLED. Thus, PhOLED performances based on the PA units are always higher than those based on the TX unit due to the higher HOMO energy levels measured for the former. In addition, STX-TXO ${ }_{2}$, with the lowest HOMO and the highest LUMO levels in the series, appears to be a very bad host material highlighting how an unsuitable combination can dramatically decrease the efficiency of a device. The potential of the DAF core is more difficult to evaluate. Indeed, the association of the DAF and $\mathrm{TXO}_{2}$ fragments with the PA unit leads to high performance devices with very similar efficiencies (Table $4, \mathrm{EQE}$ of $10.6 \%$ for SPA-TXO ${ }_{2}$ and of $10.2 \%$ for SPA-DAF at $10 \mathrm{~mA} \mathrm{~cm}{ }^{-2}$ ). However, the association of the DAF and TX fragments in STX-DAF provides a PhOLED with an EQE four times higher than that of STX-TXO $\mathbf{S}_{2}$ ( $8 \%$ vs. $1.9 \%$ respectively). The strong decrease of the LUMO level of STX-DAF compared to that of STX-TXO , $_{2}$ leading to more efficient electron injection, may be involved in this impressive difference in efficiency. However, this effect is not found for SPA-DAF vs. SPA-TXO $\mathbf{X}_{2}$ and more experiments would be therefore necessary to fully unravel this peculiar behaviour. We believe nevertheless that the potential of the TX unit is clearly not as high as that of the PA unit.

Except for STX-TXO ${ }_{2}$ for which the performance is very low both in terms of the EQE $(1.9 \%)$ and in terms of $V_{\text {on }}(6.7 \mathrm{~V})$, the D-spiro-A design seems to be promising for hosting blue phosphors. Indeed, the present device performances are higher than those reported for non-bipolar structurally related hosts

$\ddagger$ The four dyes have been also used as hosts for green $\operatorname{Ir}(\mathrm{ppy})_{3}$ and the device performances are gathered in the ESI. $\dagger$ 

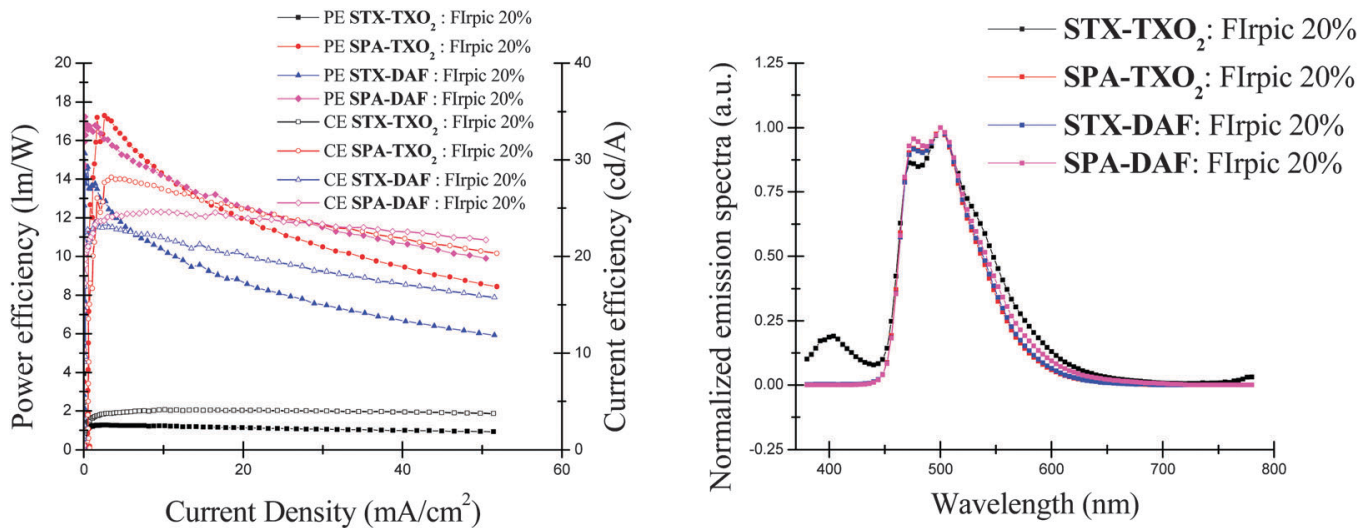

Fig. 11 Current (empty symbol) and power efficiencies (filled symbol) versus current density of the blue devices using STX-TXO $\mathbf{2}_{2}$, SPA-TXO $_{2}$, STX-DAF and SPA-DAF doped with Flrpic $20 \%$ in mass as the emitting layer (left). Corresponding EL spectra recorded at $10 \mathrm{~mA} \mathrm{~cm}^{-2}$ (right).

Table 4 Selected EL data of blue devices with an EML composed of the host doped with $20 \%$ FIrpic

\begin{tabular}{|c|c|c|c|c|c|c|c|c|}
\hline Host & $\frac{V_{\text {on }}(\mathrm{V})}{L=1^{a}}$ & \multicolumn{2}{|c|}{$\mathrm{CE}\left(\mathrm{cd} \mathrm{A}{ }^{-1}\right)$} & \multicolumn{2}{|c|}{$\underline{\mathrm{PE}\left(\operatorname{lm~W} \mathrm{W}^{-1}\right)}$} & $\frac{\mathrm{EQE}(\%)}{J=10^{b}}$ & $\frac{\operatorname{CIE}(x ; y)}{J=10}$ & $L_{\max }\left(\mathrm{cd} \mathrm{m}^{-2}\right)\left(J^{b}\right)$ \\
\hline STX-TXO $_{2}$ & 6.7 & 3.4 & 4.0 & 1.2 & 1.2 & 1.9 & $0.21 ; 0.41$ & $1300(70)$ \\
\hline STX-DAF & 3.6 & 22.5 & 22.0 & 13.7 & 10.4 & 8.0 & $0.17 ; 0.42$ & $4300(60)$ \\
\hline SPA-DAF & 2.9 & 21.7 & 24.3 & 16.4 & 14.0 & 10.2 & $0.19 ; 0.43$ & $6100(70)$ \\
\hline
\end{tabular}

such as the parent molecule SBF (EQE: $6.5 \%$ at $10 \mathrm{~mA} \mathrm{~cm}{ }^{-2}$ ). ${ }^{33}$ As the device architecture of previous work with SBF is the same as that presented herein (except for the host material), the different performance can only be attributed to the nature of the host and more particularly to the adjustments of the HOMO/ LUMO energy levels. Similarly, 4-substituted SBF hosts, recently developed by our group such as 4-phenyl-SBF (EQE: 6\%), ${ }^{33}$ 4-5-pyrimidinyl-SBF $(5 \%)^{78}$ or 4-pyridinyl-SBF ${ }^{32}$ (3.9 to $5.1 \%$ ), all lead to a lower blue PhOLED performance. Moreover, the present devices using SPA-DAF, SPA-TXO ${ }_{2}$ and STX-DAF as hosts emit light at a lower $V_{\text {on }}\left(2.9\right.$ to $3.1 \mathrm{~V}$ for $\left.L=1 \mathrm{~cd} \mathrm{~m}^{-2}\right)$ than the above mentioned 4-phenyl-SBF, ${ }^{33}$ 4-5-pyrimidinyl-SBF ${ }^{78}$ and 4-pyridinyl-SBF ${ }^{32}$ for which $V_{\text {on }}$ is higher than 4 V. SPA-DAF and SPA-TXO $\mathbf{O}_{2}$ based blue PhOLEDs even surpass the performance of those based on the known and efficient host $N, N$-dicarbazolyl-3,5benzene ( $\mathrm{mCP}, E_{\mathrm{T}}: 2.9 \mathrm{eV}$ ) previously reported in the literature with exactly the same device architecture $(\mathrm{EQE}=8.6 \%$ at $\left.10 \mathrm{~mA} \mathrm{~cm}{ }^{-2}, V_{\text {on }}=3.2 \mathrm{~V}\right){ }^{45}$ The better performance of the present hosts is due to their bipolar character, which allows a good adjustment of their HOMO/LUMO energy levels.

Interestingly, comparing the results obtained at $100 \mathrm{~cd} \mathrm{~m}^{-2}$ to those recorded at higher luminance $\left(1000 \mathrm{~cd} \mathrm{~m}^{-2}\right.$, see the ESI $\dagger$ ) shows an increase of the EQE for the three devices with SPA-TXO ${ }_{2} /$ STX-DAF and SPA-DAF as the host from 5.8/8.1 and $8.7 \%$ to $10.8 / 8.3$ and $10.2 \%$ respectively. These results show the stability and the efficiency of the devices even at high luminance.

All these features clearly highlight the efficiency of the D-spiro-A design to host the sky-blue phosphor FIrpic. Except for the device using $\mathbf{S T X}-\mathbf{T X O}_{2}$ as the host, the EL spectra of the three other devices are identical (Fig. 11, right), exclusively showing the emission of the blue dopant at 473 and $500 \mathrm{~nm}$ close to the photoluminescence of the pure FIrpic film $(475 / 500 \mathrm{~nm})$ with no parasite emission. ${ }^{77}$ The absence of other high energy emissions demonstrates an efficient energy transfer from the host to the guest. On the opposite side, the EL spectrum of the device using $\mathbf{S T X}-\mathbf{T X O}_{2}$ as the host presents in addition to the emission band of the dopant (FIrpic) another less intense emission centred at $400 \mathrm{~nm}$ in the range of the non-doped device emission (Fig. 11). This satellite emission and the lower efficiency of the device signifies a less efficient energy transfer from STX-TXO $\mathbf{O}_{2}$ to FIrpic.

\section{Conclusion}

The present work reports the synthesis, the physicochemical and photophysical properties and the application in sky-blue PhOLEDs of four high triplet organic semi-conductors based on the D-spiro-A design. This promising chemical design is based on $\pi$-conjugation disruption induced by an insulating spiro bridge between a hole transporting unit, that is, a phenylacridine (PA) or thioxanthene (TX) moiety, and an electron transporting unit, that is, a dioxothioxanthene $\left(\mathrm{TXO}_{2}\right)$ or diazafluorene (DAF) moiety. This molecular design leads to (i) a spatial separation of the HOMO and LUMO retaining a high $E_{\mathrm{T}}$, (ii) HOMO/LUMO levels of the constituting building blocks adapted to efficient charge injections and (iii) good physical properties, which are a key feature for device stability and performance. These host 
materials can be easily synthesized through a very short, efficient and highly adaptable synthetic strategy. In addition, we have shown that the properties of the dyes can be easily modulated depending on the strength of the donor/acceptor combination used, allowing adjustment of the HOMO/LUMO levels without disturbing the $E_{\mathrm{T}}$. These molecules have been incorporated as hosts in sky-blue PhOLEDs with EQEs at $10 \mathrm{~mA} \mathrm{~cm}^{-2}$ ranging from $2 \%$ to more than $10 \%$. The best performance was obtained with SPA-DAF and SPA-TXO ${ }_{2}$, highlighting the importance of the chosen donor-acceptor combination on the device performance. We believe that the D-spiro-A design is very promising to elaborate efficient host materials for blue PhOLED applications.

\section{Acknowledgements}

We wish to thank the CDIFX (Rennes) for X-ray diffraction data, the C.R.M.P.O for mass analysis, GENCI for allocation of computing time under project c2015085032 (Dr F. Barrière, Rennes), the Institut des Sciences Analytiques (Villeurbanne) for TGA, and the Service de Microanalyse-CNRS (Gif sur Yvette) for CHN analyses. MR, JRB and CP warmly thank the Région Bretagne and the ADEME for a studentship (MR), Dr B. Laffite (ADEME), the CNRS and the ANR (Projects HOME-OLED no. 11-BS07-020-01 and MEN IN BLUE no. 14-CE05-0024-01) for financial support.

\section{References}

1 B. Geffroy, P. Le Roy and C. Prat, Polym. Int., 2006, 55, 572-582.

2 H. Sasabe and J. Kido, Chem. Mater., 2011, 23, 621-630.

3 Y.-S. Tyan, J. Photonics Energy, 2011, 1, 011009.

4 R. Mertens, The OLED Handbook, A guide to OLED Technology, Industry \& Market, Ron Mertens, 2012.

5 M. Romain, D. Tondelier, J.-C. Vanel, B. Geffroy, O. Jeannin, J. Rault-Berthelot, R. Métivier and C. Poriel, Angew. Chem., Int. Ed., 2013, 52, 14147-14151.

6 N. Cocherel, C. Poriel, L. Vignau, J.-F. Bergamini and J. RaultBerthelot, Org. Lett., 2010, 12, 452-455.

7 C. Poriel, N. Cocherel, J. Rault-Berthelot, L. Vignau and O. Jeannin, Chem. - Eur. J., 2011, 17, 12631-12645.

8 D. Thirion, M. Romain, J. Rault-Berthelot and C. Poriel, J. Mater. Chem., 2012, 22, 7149-7157.

9 X. Yang, X. Xu and G. Zhou, J. Mater. Chem. C, 2015, 3, 913-944.

10 H. Liang, X. Wang, X. Zhang, Z. Liu, Z. Ge, X. Ouyang and S. Wang, New J. Chem., 2014, 38, 4696-4701.

11 C. Liu, Q. Fu, Y. Zou, C. Yang, D. Ma and J. Qin, Chem. Mater., 2014, 26, 3074-3083.

12 L. Yao, S. Sun, S. Xue, S. Zhang, X. Wu, H. Zhang, Y. Pan, C. Gu, F. Li and Y. Ma, J. Phys. Chem. C, 2013, 117, 14189-14196.

13 J.-H. Jou, S. Kumar, A. Agrawal, T.-H. Li and S. Sahoo, J. Mater. Chem. C, 2015, 3, 2974-3002.

14 M. A. Baldo, D. F. O’Brien, M. E. Thompson and S. R. Forrest, Phys. Rev. B, 1999, 60, 14422.
15 M. A. Baldo, D. F. O'Brien, Y. You, A. Shoustikob, S. Sibley, M. E. Thompson and S. R. Forrest, Nature, 1998, 395, 151-154.

16 L. Xiao, Z. Chen, B. Qu, J. Luo, S. Kong, Q. Cong and J. Kido, Adv. Mater., 2011, 23, 926-952.

17 Y. Tao, C. Yang and J. Qin, Chem. Soc. Rev., 2011, 40, 2943-2970.

18 K. S. Yook and J. Y. L. Lee, Adv. Mater., 2012, 24, 3169-3190.

19 E. Mondal, W.-Y. Hung, Y.-H. Chen, M.-H. Cheng and K.-T. Wong, Chem. - Eur. J., 2013, 19, 10563-10572.

20 C. Han, Z. Zhang, H. Xu, J. Li, G. Xie, R. Chen, Y. Zhao and W. Huang, Angew. Chem., Int. Ed., 2012, 51, 10104-10108.

21 C. W. Lee and Y. J. Lee, Chem. Mater., 2014, 26, 1616-1621.

22 M. Romain, D. Tondelier, B. Geffroy, O. Jeannin, E. Jacques, J. Rault-Berthelot and C. Poriel, Chem. - Eur. J., 2015, 21, 9426-9439.

23 C. Poriel, R. Métivier, J. Rault-Berthelot, D. Thirion, F. Barrière and O. Jeannin, Chem. Commun., 2011, 47, 11703-11705.

24 M. Romain, S. Thiery, A. Shirinskaya, C. Declairieux, D. Tondelier, B. Geffroy, O. Jeannin, J. Rault-Berthelot, R. Métivier and C. Poriel, Angew. Chem., Int. Ed., 2015, 54, 1176-1180.

25 N. Fomina, S. E. Bradforth and T. E. Hogen-Esch, Macromolecules, 2009, 42, 6440-6447.

26 S. Y. Hong, D. Y. Kim, C. Y. Kim and R. Hoffmann, Macromolecules, 2001, 34, 6474-6481.

27 S. Karabunarliev, M. Baumgarten, N. Tyutyulkov and K. Müllen, J. Phys. Chem., 1994, 98, 11892-11901.

28 B. Pan, B. Wang, Y. Wang, P. Xu, L. Wang, J. Chen and D. Ma, J. Mater. Chem. C, 2014, 2, 2466-2469.

29 S. Gong, Y.-L. Chang, K. Wu, R. White, Z.-H. Lu, D. Song and C. Yang, Chem. Mater., 2014, 26, 1463-1470.

30 C. Fan, L. Zhu, T. Liu, B. Jiang, D. Ma, J. Qin and C. Yang, Angew. Chem., Int. Ed., 2014, 53, 2147-2151.

31 M.-k. Leung, Y.-H. Hsieh, T.-Y. Kuo, P.-T. Chou, J.-H. Lee, T.-L. Chiu and H.-J. Chen, Org. Lett., 2013, 15, 4694-4697.

32 S. Thiery, D. Tondelier, C. Declairieux, B. Geffroy, O. Jeannin, R. Métivier, J. Rault-Berthelot and C. Poriel, J. Phys. Chem. C, 2015, 119, 5790-5805.

33 S. Thiery, D. Tondelier, C. Declairieux, G. Seo, B. Geffroy, O. Jeannin, J. Rault-Berthelot, R. Métivier and C. Poriel, J. Mater. Chem. C, 2014, 2, 4156-4166.

34 M.-k. Leung, W.-H. Yang, C.-N. Chuang, J.-H. Lee, C.-F. Lin, M.-K. Wei and Y.-H. Liu, Org. Lett., 2012, 14, 4986-4989.

35 C. Fan, Y. Chen, Z. Liu, Z. Jiang, C. Zhong, D. Ma, J. Qin and C. Yang, J. Mater. Chem. C, 2013, 1, 463-469.

36 J. Zhao, G.-H. Xie, C.-R. Yin, L.-H. Xie, C.-M. Han, R.-F. Chen, H. Xu, M.-D. Yi, Z.-P. Deng, S.-F. Chen, Y. Zhao, S.-Y. Liu and W. Huang, Chem. Mater., 2011, 23, 5331-5339.

37 F. May, M. Al-Helwi, B. Baumeier, W. Kowalsky, E. Fuchs, C. Lennartz and D. Andrienko, J. Am. Chem. Soc., 2012, 134, 13818-13822.

38 J.-K. Bin, N.-S. Cho and J.-I. Hong, Adv. Mater., 2012, 24, 2911-2915.

39 J. Ding, Q. Wang, L. Zhao, D. Ma, L. Wang, X. Jing and F. Wang, J. Mater. Chem., 2010, 20, 8126-8133. 
40 H. Ohkuma, T. Nakagawa, K. Shizu, T. Yasuda and C. Adachi, Chem. Lett., 2014, 43, 1017-1019.

41 K. Nasu, T. Nakagawa, H. Nomura, C.-J. Lin, C.-H. Cheng, M.-R. Tseng, T. Yasuda and C. Adachi, Chem. Commun., 2013, 49, 10385-10387.

42 C.-J. Lin, H.-L. Huang, M.-R. Tseng and C.-H. Cheng, J. Disp. Technol., 2009, 5, 236-240.

43 Y.-X. Zhang, L. Zhang, L.-S. Cui, C.-h. Gao, H. Chen, Q. Li, Z.-Q. Jiang and L.-S. Liao, Org. Lett., 2014, 16, 3748-3751.

44 L. Ding, S.-C. Dong, Z.-Q. Jiang, H. Chen and L.-S. Liao, Adv. Funct. Mater., 2015, 25, 645-650.

45 M. Romain, D. Tondelier, B. Geffroy, A. Shirinskaya, O. Jeannin, J. Rault-Berthelot and C. Poriel, Chem. Commun., 2015, 51, 1313-1315.

46 B.-C. Wang, H.-R. Liao, J.-C. Chang, L. Chen and J.-T. Yeh, J. Lumin., 2007, 127, 333-342.

47 G. Méhes, H. Nomura, Q. Zhang, T. Nakagawa and C. Adachi, Angew. Chem., Int. Ed., 2012, 51, 11311-11315.

48 Z. Jiang, Z. Liu, C. Yang, C. Zhong, J. Qin, G. Yu and Y. Liu, Adv. Funct. Mater., 2009, 19, 3987-3995.

49 T. Liu, H. Sun, C. Fan, D. Ma, C. Zhong and C. Yang, Org. Electron., 2014, 15, 3568-3576.

50 H. Chen, Z.-Q. Jiang, C.-H. Gao, M.-F. Xu, S.-C. Dong, L.-S. Cui, S.-J. Ji and L.-S. Liao, Chem. - Eur. J., 2013, 19, 11791-11797.

51 C.-Y. Chan, Y.-C. Wong, M.-Y. Chan, S.-H. Cheung, S.-K. So and V. W.-W. Yam, Chem. Mater., 2014, 26, 6585-6594.

52 Q. Zhang, J. Li, K. Shizu, S. Huang, S. Hirata, H. Miyazaki and C. Adachi, J. Am. Chem. Soc., 2012, 134, 14706-14709.

53 H. Li, A. S. Batsanov, K. C. Moss, H. L. Vaughan, F. B. Dias, K. T. r. Kamtekar, M. R. Bryce and A. P. Monkman, Chem. Commun., 2010, 46, 4812-4814.

54 Y. Li, Z. Wang, X. Li, G. Xie, D. Chen, Y.-F. Wang, C.-C. Lo, A. Lien, J. Peng, Y. Cao and S.-J. Su, Chem. Mater., 2015, 27, 1100-1109.

55 S.-J. Kim, J. Leroy, C. Zuniga, Y. Zhang, L. Zhu, J. S. Sears, S. Barlow, J.-L. Brédas, S. R. Marder and B. Kippelen, Org. Electron., 2011, 12, 1314-1318.

56 H. Sasabe, Y. Seino, M. Kimura and J. Kido, J. Mater. Chem., 2012, 24, 1404-1406.

57 F.-M. Hsu, C.-H. Chien, Y.-J. Hsieh, C.-H. Wu, C.-F. Shu, S.-W. Liu and C.-T. Chen, J. Mater. Chem., 2009, 19, 8002-8008.

58 S. O. Jeon, T. Earmme and S. A. Jenekhe, J. Mater. Chem. C, 2014, 2, 10129-10137.

59 K.-T. Wong, R.-T. Chen, F.-C. Fang, C.-c. Wu and Y.-T. Lin, Org. Lett., 2005, 7, 1979-1982.
60 W.-Y. Hung, T.-C. Wang, H.-C. Chiu, H.-F. Chen and K.-T. Wong, Phys. Chem. Chem. Phys., 2010, 12, 10685-10687.

61 H.-F. Chen, T.-C. Wang, W.-Y. Hung, H.-C. Chiu, C. Yun and K.-T. Wong, J. Mater. Chem., 2012, 22, 9658-9664.

62 C.-C. Chi, C.-L. Chiang, S.-W. Liu, H. Yueh, C.-T. Chen and C.-T. Chen, J. Mater. Chem., 2009, 19, 5561-5571.

63 W.-J. Li, B. Liu, Y. Qian, L.-H. Xie, J. Wang, S.-B. Li and W. Huang, Polym. Chem., 2013, 4, 1796-1802.

64 M. Hong, K. Zhang, Y.-Z. Li and J. Zhu, Polyhedron, 2009, 28, 445-452.

65 X. Li, H.-J. Chi, G.-H. Lu, G.-Y. Xiao, Y. Dong, D.-Y. Zhang, Z.-Q. Zhang and Z.-Z. Hu, Org. Electron., 2012, 13, 3138-3144.

66 C.-C. Wang, C.-H. Yang, S.-M. Tseng, S.-Y. Lin, T.-Y. Wu, M.-R. Fuh, G.-H. Lee, K.-T. Wong, R.-T. Chen, Y.-M. Cheng and P.-T. Chou, Inorg. Chem., 2004, 43, 4781-4783.

67 H.-F. Chen, K.-T. Wong, Y.-H. Liu, Y. Wang, Y.-M. Cheng, M.-W. Chung, P.-T. Chou and H.-C. Su, J. Mater. Chem., 2011, 21, 768-774.

68 H.-F. Chen, W.-Y. Hung, S.-W. Chen, T.-C. Wang, S.-W. Lin, S.-H. Chou, C.-T. Liao, H.-C. Su, H.-A. Pan, P.-T. Chou, Y.-H. Liu and K.-T. Wong, Inorg. Chem., 2012, 51, 12114-12121.

69 C.-J. Zheng, J. Ye, M.-F. Lo, M.-K. Fing, X.-M. Ou, X.-H. Zhang and C.-S. Lee, Chem. Mater., 2012, 24, 643-650.

70 M. J. Plater, S. Kemp and E. Lattmann, J. Chem. Soc., Perkin Trans. 1, 2000, 971-979.

71 G. R. Fulmer, A. J. M. Miller, N. H. Sherden, H. E. Gottlieb, A. Nudelman, B. M. Stoltz, J. E. Bercaw and K. I. Goldberg, Organometallics, 2010, 29, 2176-2179.

72 T. P. I. Saragi, T. Spehr, A. Siebert, T. Fuhrmann-Lieker and J. Salbeck, Chem. Rev., 2007, 107, 1011-1065.

73 C. Poriel, J.-J. Liang, J. Rault-Berthelot, F. Barrière, N. Cocherel, A. M. Z. Slawin, D. Horhant, M. Virboul, G. Alcaraz, N. Audebrand, L. Vignau, N. Huby, G. Wantz and L. Hirsch, Chem. - Eur. J., 2007, 13, 10055-10069.

74 R. Badiello, E. M. Fielden and S. C. Lillicrap, Int. J. Radiat. Phys. Chem., 1973, 5, 173-181.

75 R. P. Thummel, F. Lefoulon and R. Mahadevan, J. Org. Chem., 1985, 50, 3824-3828.

76 C.-C. Lee, M.-k. Leung, P.-Y. Lee, T.-L. Chiu, J.-H. Lee, C. Liu and P.-T. Chou, Macromolecules, 2012, 45, 751-765.

77 E. Baranoff and B. F. E. Curchod, Dalton Trans., 2015, 44, 8318-8329.

78 S. Thiery, C. Declairieux, D. Tondelier, G. Seo, B. Geffroy, O. Jeannin, R. Métivier, J. Rault-Berthelot and C. Poriel, Tetrahedron, 2014, 70, 6337-6351. 